\title{
Inhibition of mTOR-kinase destabilizes MYCN and is a potential therapy for MYCN-dependent tumors
}

Lynsey Vaughan ${ }^{1,9}$, Paul A. Clarke ${ }^{2}$, Karen Barker ${ }^{1}$, Yvan Chanthery ${ }^{3}$ Clay W. Gustafson ${ }^{3}$, Elizabeth Tucker ${ }^{1}$, Jane Renshaw ${ }^{1}$, Florence Raynaud ${ }^{4}$, Xiaodun Li $^{1,11}$, Rosemary Burke ${ }^{5}$, Yann Jamin ${ }^{6}$, Simon P. Robinson ${ }^{6}$, Andrew Pearson ${ }^{1}$, Michel Maira ${ }^{7,10}$, William A. Weiss ${ }^{3}$, Paul Workman² and Louis Chesler ${ }^{1,2,8}$

${ }^{1}$ Division of Clinical Studies, The Institute of Cancer Research, Sutton, Surrey, UK

2 Cancer Research UK Cancer Therapeutics Unit, The Institute of Cancer Research, Signal Transduction and Molecular Pharmacology Team, The Institute of Cancer Research, Sutton, Surrey, UK

${ }^{3}$ Department of Neurology, Pediatrics, Neurosurgery, Brain Tumor Research Center and Helen Diller Family Comprehensive Cancer Center, University of California, San Francisco, CA, USA

${ }^{4}$ Cancer Research UK Cancer Therapeutics Unit, Clinical Pharmacology and Trials Team, Sutton, Surrey, UK

${ }^{5}$ Cancer Research UK Cancer Therapeutics Unit, The Institute of Cancer Research, Target Selection and Hit Discovery Team, The Institute of Cancer Research, Sutton, Surrey, UK

${ }^{6}$ Cancer Research UK \& Engineering and Physical Sciences Research Council Cancer Imaging Centre, The Institute of Cancer Research, Sutton, Surrey, UK

${ }^{7}$ Novartis Pharma AG, Basel, Switzerland

${ }^{8}$ The Royal Marsden NHS Trust, Children and Young People's Unit, Sutton, Surrey, UK

${ }^{9}$ Present address: Cell Signalling Group, Cancer Research UK Manchester Institute, The University of Manchester, Manchester, UK

${ }^{10}$ Present address: Basilea Pharmaceutica International AG, Basel, Switzerland

${ }^{11}$ Present address: MRC Cancer Unit, University of Cambridge, Cambridge, UK

Correspondence to: Lovis Chesler, email: lovis.chesler@icr.ac.uk

Keywords: neuroblastoma, mTOR, MYC, MYCN, PI3-kinase

Received: April 29, $2016 \quad$ Accepted: June 01, $2016 \quad$ Published: July 12, 2016

\section{ABSTRACT}

MYC oncoproteins deliver a potent oncogenic stimulus in several human cancers, making them major targets for drug development, but efforts to deliver clinically practical therapeutics have not yet been realized. In childhood cancer, aberrant expression of MYC and MYCN genes delineates a group of aggressive tumours responsible for a major proportion of pediatric cancer deaths. We designed a chemical-genetic screen that identifies compounds capable of enhancing proteasomal elimination of MYCN oncoprotein. We isolated several classes of compound that selectively kill MYCN expressing cells and we focus on inhibitors of PI3K/mTOR pathway in this study. We show that PI3K/mTOR inhibitors selectively killed MYCNexpressing neuroblastoma tumor cells, and induced significant apoptosis of transgenic MYCN-driven neuroblastoma tumors concomitant with elimination of MYCN protein in vivo. Mechanistically, the ability of these compounds to degrade MYCN requires complete blockade of mTOR but not PI3 kinase activity and we highlight NVP-BEZ235 as a PI3K/mTOR inhibitor with an ideal activity profile. These data establish that MYCN expression is a marker indicative of likely clinical sensitivity to mTOR inhibition, and provide a rationale for the selection of clinical candidate MYCN-destabilizers likely to be useful for the treatment of MYCN-driven cancers.

\section{INTRODUCTION}

Aberrant expression of the transcription factors
MYC and MYCN (a MYC homologue with expression limited to undifferentiated neurons) delivers a potent oncogenic stimulus in cancer, making MYC oncoproteins 
attractive targets for pharmacologic inhibition [1-7]. In pediatric cancer, expression of $\mathrm{MYCN}$ is selectively confined to tumor tissue in medulloblastoma [8], neuroblastoma [1, 2], rhabdomyosarcoma [7], and a subset of retinoblastoma [9], four common solid tumors that together account for a substantial proportion of relapsed cancer deaths in children. Pharmacologic inhibition of MYCN oncoprotein is therefore of great interest in pediatric cancer; however, direct targeting of $\mathrm{MYCN}$, or MYC oncoproteins in general, has not yet delivered viable therapeutics to the clinic.

A substantial body of work suggests two approaches by which MYC proteins could be therapeutically targeted. First, synthetic lethal interactions are generated by persistent overexpression of MYC in cancer cells and impart therapeutic sensitivity [10-16]. Genetic screens utilizing RNA-interference have identified relationships between expression of MYC and a defined set of additional genes, suppression of which induces lethality restricted to cells with MYC or MYCN expression (CDK1, CDK2, AURKA, AURKB, CHK1) [10-12, 17-23]. Second, MYC-family oncoproteins are oncogenically stabilized by altered phosphorylation within an N-terminal conserved phosphodegron domain (CPD) [14, 24-26]. Binding to the CPD is a function of the ubiquitin ligases (FBW7, HUWE1) and is required for initiation of proteasomal degradation [4, 24, 27]. Phosphorylation of conserved T58 and $\mathrm{S} 62$ residues within the CPD is regulated by CDK1 (a MAPK target), and by the PI3K/AKT-regulated targets GSK3 $\beta$ and mTOR, respectively [28-30]. Cancers defined by mutations in FBW7 (which disrupt the association of FBW7 with the CPD-client protein) are characterized by elevated levels of the CPD-client oncoproteins MYC [31], c-Jun [32], cyclin E [33] and NOTCH [34]. Aberrant stimulation of MAPK or PI3K pathways also contributes to oncogenic stabilization of MYCN in certain cancers. In neuroblastoma, enhanced PI3K signaling correlates with poor prognosis and aggressive tumor biology [35, 36]. Previous work established that in cancer cell lines, excess PI3K pathway signaling modulates the AKT-regulated targets GSK3 $\beta$ and mTOR, extending the half-life of MYC and outlining a potential pharmacologic approach for targeting MYC stability [28-30, 34, 37].

To our knowledge, a chemical-genetic screen that addresses these two mechanisms, corroborating previous synthetic lethality studies of MYC oncogene expression or providing the targets for MYC oncoprotein destabilization, has not been reported. With this in mind, we designed a cell-based screen utilizing an isogenically derived set of neuroblastoma cells with either high-level expression of wild-type MYCN or with genetically modified, stabilized MYCN (lacking the CPD target phosphorylation residues, T58 and S62). Potent compounds that have mechanistic activity in cells expressing wild-type, but not CPD mutated, MYCN protein should antagonize oncogenic stabilization of MYCN protein and target synthetic lethal relationships associated with $\mathrm{MYCN}$ expression. We outline a strategy to identify compounds that specifically target wild-type MYCN protein and present a chemical screen that identifies small-molecules with the ability to indirectly pharmacologically target MYCN (and potentially MYC) protein. Compounds inhibiting several genetic pathways were identified in the screen and in this study we characterize small-molecule inhibitors of the PI3K/mTOR pathway. We show that inhibitors of PI3K/ mTOR, or mTOR kinase activity alone, exhibit selective activity against cells that express high-levels of MYCN protein. NVP-BEZ235, a potent inhibitor of both PI3K and mTOR-kinases, which is already in clinical trials for PI3K pathway-mutated adult cancers, eliminated intratumoral MYCN and induced regression of MYCN-driven transgenic neuroblastoma tumors in vivo.

Overall our observations raise the exciting possibility that a group of poor-outcome pediatric cancers could be effectively targeted through their expression of a tumor-specific oncoprotein, using available and clinically tested therapeutics.

\section{RESULTS}

\section{Screen for small-molecules that target MYCN oncoprotein stability}

We designed a focused chemical-genetic screen that would identify small-molecules with a mechanistic ability to target cells expressing high-levels of wildtype MYCN. Expression constructs encoding FLAGtagged wild type or stabilized (CPD-mutated) MYCN proteins were transfected into human neuroblastoma cells lacking endogenous MYCN expression. Equivalent levels of MYCN expression were achieved in SHEP cells expressing wild-type MYCN (SHEP WT) in comparison to a range of established, tumor-derived neuroblastoma cell lines known to express high-levels of MYCN (Figure $\mathrm{S} 1 \mathrm{~A})$. However, elevated levels of $\mathrm{MYCN}$ expression were observed in SHEP cells expressing mutated MYCN (SHEP T58, SHEP S62 and SHEP T58/S62) in comparison with both SHEP WT and established neuroblastoma cell lines - consistent with the stabilization of CPD-mutated MYCN (Figure S1A, B). SHEP cells expressing both wild type and mutant MYCN proteins all exhibited significantly increased cellular proliferation in comparison to parental SHEP cells but not to each other (Figure S1C).

To establish the MYCN dependency of both the native neuroblastoma cell line Kelly and the SHEP WT and SHEP T58/S62 mutant MYCN lines, we abrogated MYCN expression via siRNA-mediated knockdown. Inhibition of MYCN in the Kelly cell line induced cell death as measured by trypan blue exclusion (Figure S1D) and similarly, although to a lesser extent, MYCN 
cell viability was diminished with siRNA treatment in both SHEP WT and SHEP T58/S62 neuroblastoma cell lines (Figure S1E, F), confirming that exogenous MYCN expression is responsible for the increased proliferation observed in SHEP WT and SHEP T58/S62 cells.

Using cellular proliferation as an endpoint, we selected for compounds with enhanced activity against SHEP WT cells compared to SHEP T58/S62 cells expressing stabilized MYCN. We reasoned that this selection would enrich for compounds with mechanistic activity against MYCN but exclude compounds with generic activity related to inhibition of cell proliferation rather than MYCN stability. The screen was performed using an in-house kinase inhibitor library of 228 compounds at low, intermediate and high concentrations (40nM, 200nM and $1 \mu \mathrm{M})$ to identify compounds that exhibit on-target effects whilst excluding the possibility of off-target effects exerted by kinase inhibitors at excessive concentrations $(>1 \mu \mathrm{M})$. The top 25 ranked inhibitors that showed selective inhibition of SHEP WT cells included inhibitors of JAK/STAT pathway, receptor tyrosine kinases (PDGFR), PI3K pathway (PI3K, AKT and mTOR), and cell cycle checkpoints (AURKA, AURKB, CDK, PLK, WEE1 and CHK1) (Figure 1A).

The specificity of 17 of the inhibitors in this list has been profiled against a panel of 300 protein kinases [38]. Several demonstrate off-target activity, with 6 (JAK Inhibitor I, SU6656, SU11652, JAK3 Inhibitor VI, PKR Inhibitor and Aurora Kinase/Cdk Inhibitor) inhibiting $>25$ kinases by $>75 \%$, and a further 3 (PDGF RTK Inhibitor, PDGF Receptor Tyrosine Kinase Inhibitor IV and Cdk2 Inhibitor IV-NU6140) inhibiting $>5$ kinases. Of these, 5 had activity against both Aurora A and B (Jak inhibitor I, SU6656, PDGF RTK inhibitor, PKR inhibitor, Aurora kinase/CDK inhibitor), Aurora A (Cdk2 Inhibitor IVNU6140) or Aurora B (Jak3 VI inhibitor). The JAK inhibitor I also inhibited CHK1 and PLK1, CHK1 was also inhibited by SU11652 and the JAK3 VI inhibitor, and CDK1 was inhibited by the JAK3 VI inhibitor, PKR inhibitor and the Aurora Kinase/Cdk Inhibitor. The offtarget and on-target activity of several of these inhibitors included AURA [12], AURB [39], CDK1 [10] and CHK1 [17] that have been reported to regulate MYCN stability or exhibit a synthetic lethal interaction with MYCN dependence. Our focused screen therefore appears to have strong predictive ability to identify compounds that are selective inhibitors of cells expressing MYCN protein. This chemically driven screen appears to validate previous RNAi driven loss-of-function studies, which highlighted the potential for pharmacologic targeting of synthetic lethal interactions in MYCN expressing cancers.

\section{PI3K pathway inhibitors selectively target cells with MYCN expression}

Potent and selective inhibitors of PI3K and/or mTOR pathways have entered clinical trials in both adult and pediatric cancers, and could be valuable agents for treatment of childhood cancers [40, 41]. The fact that PI103 , a potent and highly specific small-molecule inhibitor of class I PI3K and mTOR [42-44] preferentially targeted MYCN-expressing cells in our screen was of particular interest to us. Preliminary studies demonstrated that LY294002, a first-generation, weak inhibitor of PI3K pathway that has off-target liabilities [45], destabilized MYCN and could partially inhibit the growth of MYCNdriven neuroblastoma tumors [46] but its use was limited by the off-target toxicity profile of LY294002, which restricted in vivo dosing. Given the activity of PI-103 (a more potent and selective inhibitor of PI3K signaling than LY294002) in our focused screen, and the availability of additional potent and selective PI3K inhibitors for clinical use, we focused on the role of PI3K/mTOR signaling in MYCN stability (Table S1).

We first re-confirmed our initial observation that the proliferation of SHEP WT cells was preferentially inhibited by PI-103 treatment using a trypan blue exclusion assay (Figure 1B). SHEP WT cells exhibited a 4.8-fold and 2.9-fold increased sensitivity to PI-103 compared to the parent SHEP cells or SHEP T58/S62 respectively. This differential sensitivity pattern was reproduced with NVPBEZ235 [47], an imidazo-[4,5-c]-quinoline derivative PI3K and mTOR inhibitor (7.1 and 4.7-fold respectively), and also with Torin1 [48], an ATP-competitive mTORkinase (mTORC1 and mTORC2) inhibitor lacking PI3K inhibition, and to a lesser degree with ZSTK474 [49], a pan class I PI3K inhibitor that has poor activity against mTOR (3.8 and 3.2-fold respectively). In addition, the native neuroblastoma Kelly cells also exhibited a similar sensitivity profile as the SHEP WT cells (Figure 1B). These results show a clear trend in drug sensitivity where inhibition of cell proliferation aligns with the degree of $M Y C N$ amplification and protein expression. Our findings were reinforced both in an independent sulforhodamine B (SRB) assay of cell proliferation, and also in a larger cell panel that included four primary neuroblastoma cell lines with $M Y C N$ gene amplification, three cell lines with diploid $M Y C N$ and four engineered SHEP cell lines expressing mutated or wild-type exogenous MYCN protein (Table S2). Furthermore, TGX221, an isoform-selective p110 $\beta$ selective PI3K inhibitor and rapamycin, a non-ATP site and incomplete inhibitor of mTOR (mTORC1-specific), showed relatively non-specific activity against this panel. The activity of NVP-BEZ235 and Torin1 against Kelly and three additional $M Y C N$-amplified neuroblastoma cell lines correlated with induction of apoptosis in the Kelly cell line by two independent assays (Figure 1D, 1E). This data suggests that within the spectrum of available 
A

\begin{tabular}{rccc} 
& $\mathbf{4 0 n M}$ & $\mathbf{2 0 0 n M}$ & $\mathbf{1 0 0 0 n M}$ \\
JAK Inhibitor I & $\mathbf{0 . 8 8}$ & $\mathbf{1 . 0 1}$ & 5.37 \\
PI-103 (class I PI3K/mTOR) & 1.01 & $\mathbf{1 . 4 7}$ & 5.07 \\
AKT Inhibitor V,Triciribine & 1.20 & 2.87 & 3.29 \\
SU6656 (PDGFR/VEGFR/FGFR) & $\mathbf{0 . 8 7}$ & $\mathbf{0 . 9 7}$ & 2.90 \\
ER 27319 maleate (SYK) & 0.92 & $\mathbf{1 . 6 7}$ & 2.83 \\
BIO (GSK3) & 0.97 & $\mathbf{1 . 0 5}$ & 2.77 \\
SU11652 (PDGFR/VEGFR/FGFR) & 0.98 & $\mathbf{0 . 8 6}$ & 2.55 \\
IC262 (Casein kinase I) & 1.14 & $\mathbf{2 . 0 5}$ & 2.40 \\
IKK16 (IkB kinase) & 1.02 & $\mathbf{1 . 0 8}$ & 2.39 \\
Ki 8751 (PDGFR/VEGFR/FGFR/KIT) & 1.00 & $\mathbf{0 . 9 5}$ & 2.32 \\
PDGF RTK Inhibitor & 1.07 & $\mathbf{1 . 1 3}$ & 2.14 \\
AKT Inhibitor V,Triciribine & 1.18 & $\mathbf{2 . 0 5}$ & 2.01 \\
GW 843682X (PLK1/3) & 0.92 & $\mathbf{1 . 4 5}$ & 1.92 \\
EGFR Inhbitor & 1.37 & $\mathbf{1 . 6 7}$ & 1.87 \\
Sphingosine Kinase Inhibitor & 1.15 & $\mathbf{1 . 0 5}$ & 1.84 \\
JAK3 Inhibitor VI & $\mathbf{0 . 8 3}$ & $\mathbf{0 . 9 0}$ & 1.81 \\
PDGFR RTK Inhibitor IV & $\mathbf{2 . 2 3}$ & $\mathbf{1 . 8 3}$ & 1.75 \\
Cdk2 Inhibitor, NU6140 & $\mathbf{0 . 9 1}$ & $\mathbf{0 . 8 7}$ & 1.75 \\
MK2a Inhibitor (MAPKAPK2) & 1.05 & $\mathbf{1 . 7 3}$ & 1.69 \\
Rapamycin (mTORC1) & 1.00 & $\mathbf{1 . 1 2}$ & 1.64 \\
PKR Inhibitor & 1.05 & $\mathbf{1 . 7 4}$ & 1.63 \\
Aurora Kinase/Cdk Inhibitor & 0.92 & $\mathbf{0 . 9 2}$ & 1.48 \\
PD 407824 (CHK1/WWE1) & 0.98 & $\mathbf{1 . 0 7}$ & 1.45 \\
ZM447439 (Aurora B) & 1.13 & $\mathbf{1 . 3 1}$ & 1.41 \\
MNK1 Inhibitor & 1.02 & $\mathbf{1 . 0 8}$ & 1.41 \\
\hline
\end{tabular}

B

\begin{tabular}{|c|c|c|c|c|c|c|}
\hline & & & \multicolumn{4}{|c|}{$\mathrm{Gl}_{50}(\mu \mathrm{M})$} \\
\hline Cell line & MYCN protein & MYCN Status & PI-103 & NVP-BEZ235 & Torin1 & ZSTK474 \\
\hline Kelly & High & Wild-type & $0.28+/ 0.02$ & $0.017+/-0.07$ & $0.023+1-0.08$ & $0.15+/ 0.07$ \\
\hline SHEP WT & High & Wild-type & $0.42+10.03$ & $0.091+\mid-0.02$ & $0.102+1-0.09$ & $0.35+1-0.02$ \\
\hline SHEP T58/S62 & High & $\begin{array}{l}\text { Mutated at CDK1 } \\
\text { /GSK } 3 \beta \text { site }\end{array}$ & $1.22+10.32$ & $0.43+1-0.018$ & $0.810+/-0.01$ & $1.09+1-0.04$ \\
\hline SHEP & No expression & No MYCN & $2.02+10.08$ & $0.712+/-0.21$ & $0.912+I-0.11$ & $1.31+/-0.03$ \\
\hline
\end{tabular}

D

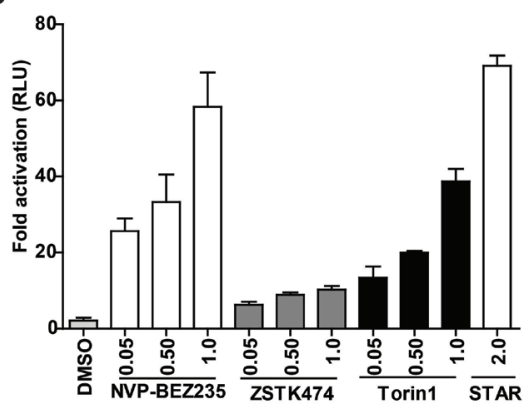

E

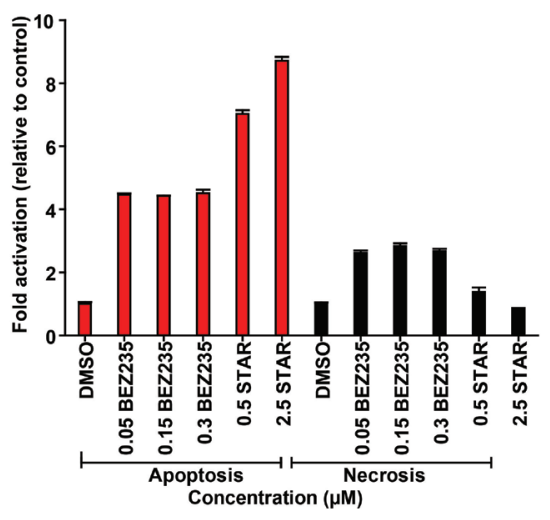

C

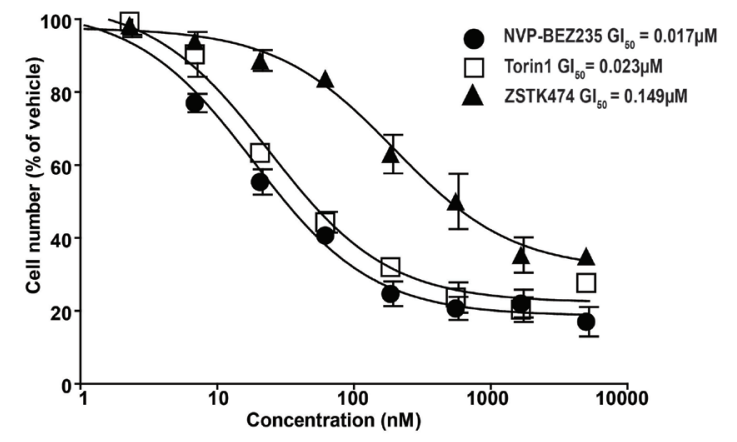

F

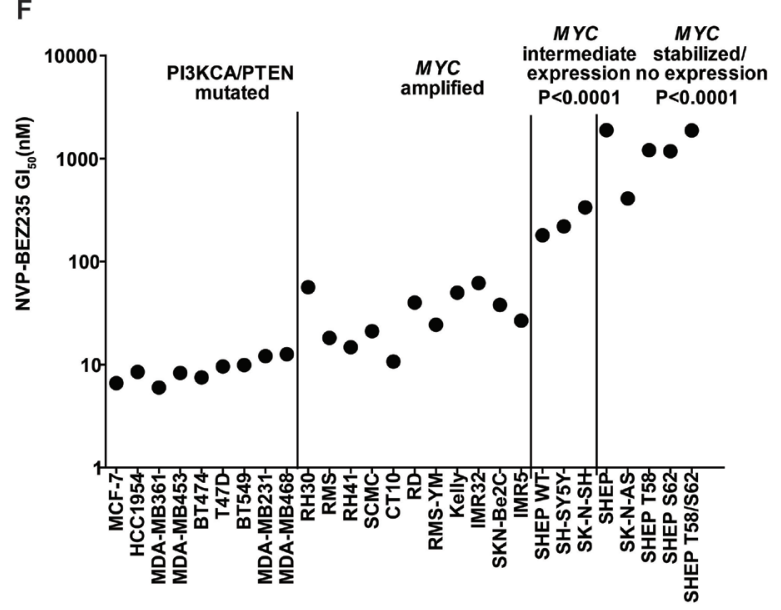

Figure 1: Identification of PI3K/mTOR inhibitors that selectively target MYCN-expressing tumor cells. A. SHEP WT and SHEP T58/S62 cells were treated at a concentration of 40, 200 and 1000nM for $96 \mathrm{~h}$ with a panel of 228 kinase inhibitors exhibiting a range of kinome inhibitory properties. Cell viability was determined using CellTiter-blue reagent. The $\mathrm{Z}$ factor for all assay plates was $>0.5$. The data are displayed as a ratio of SHEP T58/S62:SHEP WT, increased red indicates increased activity in SHEP WT compared to SHEP T58/S62 cells. B. Cell viability as determined by trypan blue exclusion method in Kelly, SHEP, SHEP WT and SHEP T58/S62 neuroblastoma cells. Cells were treated for $72 \mathrm{~h}$ with PI-103, NVP-BEZ235, Torin 1 or ZSTK474. Mean GI ${ }_{50}$ and standard error from three independent assays are shown. C. Representative log curves of Kelly cells treated for $72 \mathrm{~h}$ with, NVP-BEZ235, Torin1 or ZSTK474. Values represent the averages of three independent assays. Error bars; standard deviation. D. Induction of apoptosis $24 \mathrm{~h}$ post treatment with DMSO, NVP-BEZ235, ZSTK474, Torin1 or Staurosporine (as a positive control) in Kelly neuroblastoma cells as measured by CaspaseGlo 3/7 cleavage assay. Values are fold activation of caspase activity normalised to DMSO control and are averages of three assays. Error bars; standard deviation. E. Induction of apoptosis and necrosis by NVP-BEZ235. Kelly cells were treated with NVP-BEZ235 or Staurosporine (STAR) as a positive inducer of apoptosis and cell apoptosis and necrosis assessed via Cell Death ELISA (Roche ${ }^{\mathrm{TM}}$ ) $24 \mathrm{~h}$ post treatment. (Apoptosis; red bars and necrosis; black bars). Values are fold induction of histone-associated DNA fragments normalized to DMSO control and are averages of three assays. Error bars; standard deviation. F. Growth inhibitory $\left(\mathrm{GI}_{50} \mathrm{~s}\right)$ values carried out at $72 \mathrm{~h}$ using the SRB assay of a panel of adult cancer cell lines carrying PIK3CA/PTEN mutations compared with pediatric cancer cell lines containing a spectrum of $M Y C C / N$ gene copy number or mutated $M Y C N$. See also Figure 1B and Table S2. 
$\mathrm{PI} 3 \mathrm{~K} / \mathrm{mTOR}$ pathway-active compounds, selective mTOR kinase inhibitors or dual inhibitors of PI3K and mTOR kinases are most likely to exhibit potent activity in neuroblastoma cells that express MYCN.

\section{Expression of MYCN selectively sensitizes cells to PI3K/mTOR inhibition}

The enhanced sensitivity of MYCN overexpressing
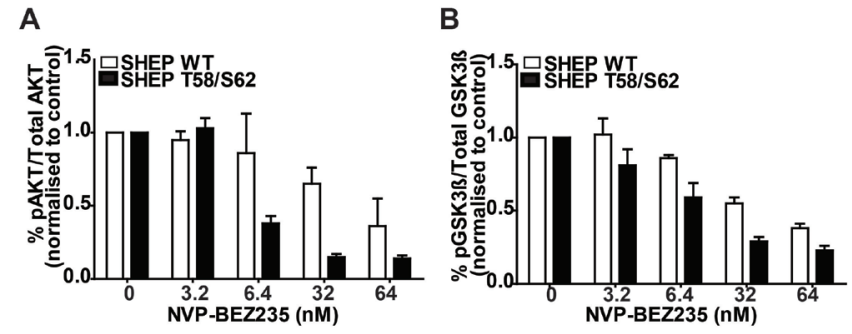

C

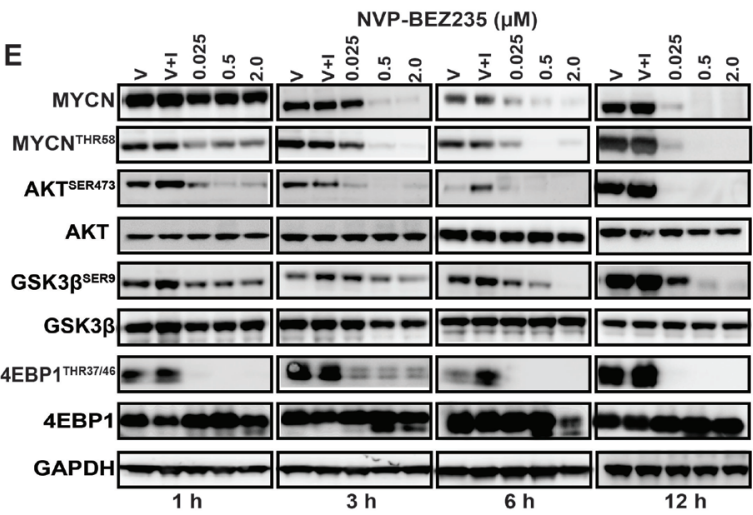

G

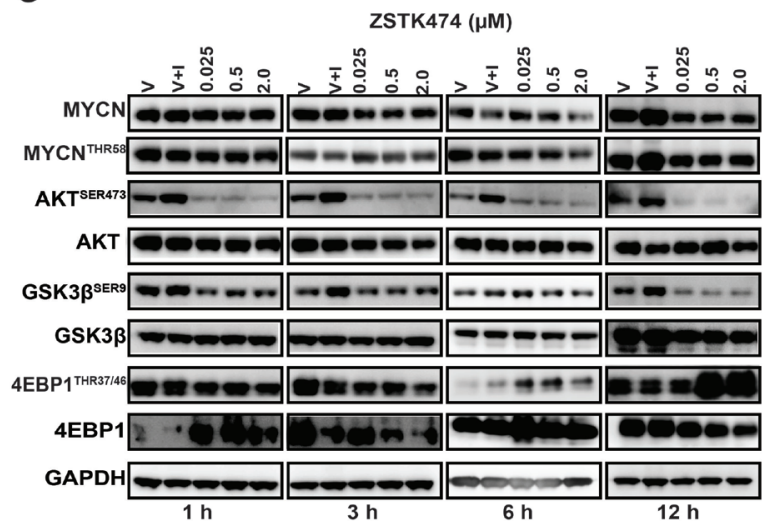

$\mathbf{F}$

H
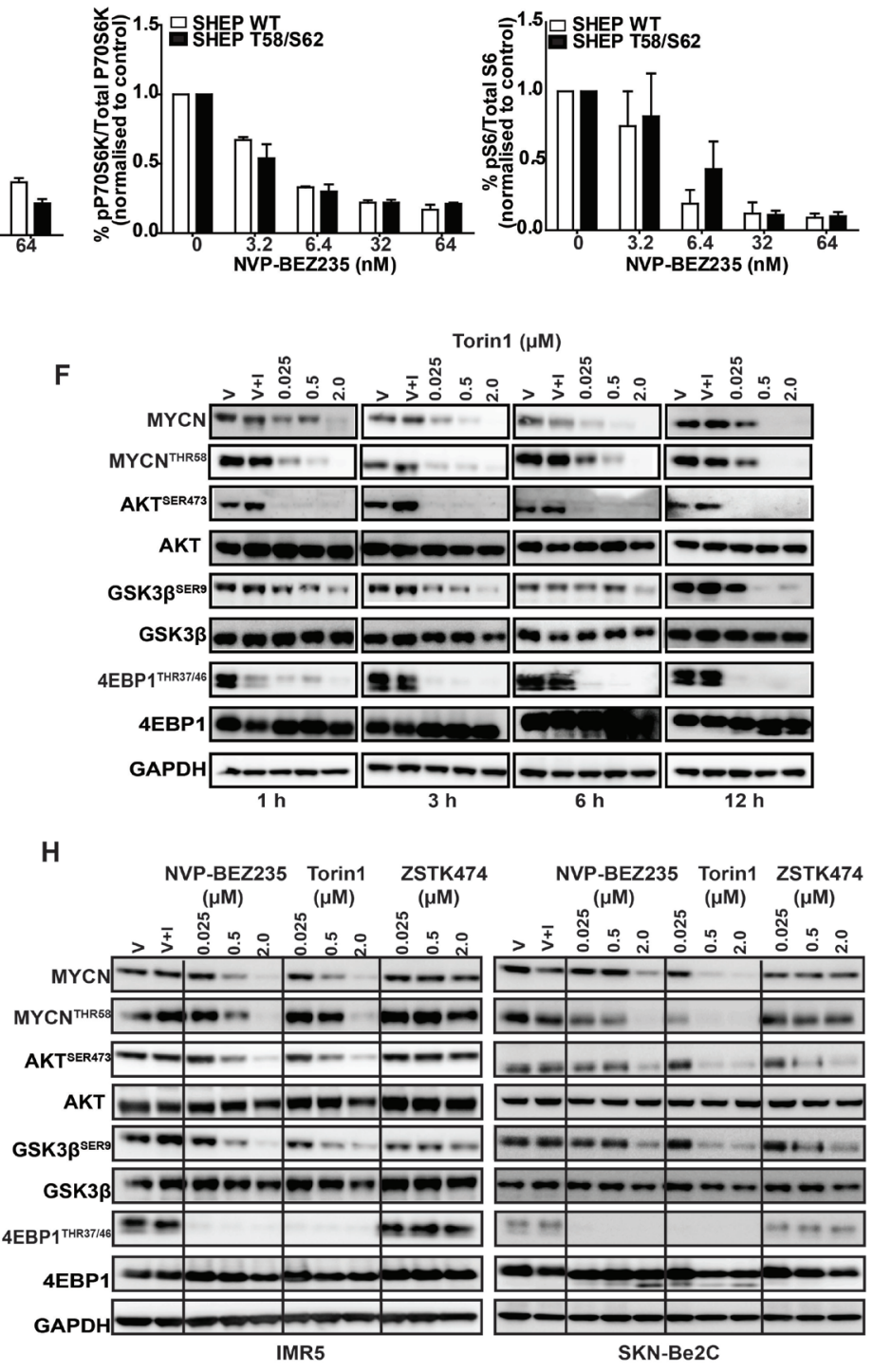

Figure 2: Inhibition of PI3K/mTOR signaling destabilizes MYCN. A.-D. Mesoscale Discovery (MSD) analysis of PI3K/mTOR signaling components AKT ${ }^{\mathrm{SER} 473}$,GSK3 $\beta^{\text {SER9 }}$, pP70S6K ${ }^{\text {THR389 }}$ and RPS6 ${ }^{\text {SER240/244 }}$ SHEP WT and SHEP T58/S62 cell lysates were collected 3 $\mathrm{h}$ after treatment with NVP-BEZ235 and analysed for inhibitory effects on the phosphorylation of AKT ${ }^{\text {SER } 473}$, GSK3 $\beta^{\text {SER9 }}$, RPS6 ${ }^{\text {SER240/244 }}$ and pP70S6K ${ }^{\text {THR389 }}$. Analysis was performed in triplicate using the MesoScale Discovery assay. Data are expressed as percent of control and values are shown as mean + SEM. E.-G. Immunoblotting analyses of time and concentration dependent effects of NVP-BEZ235, ZSTK474 and Torin1 treatment on MYCN stability and PI3K/mTOR biomarker AKT ${ }^{\text {SER473 }}$, GSK3 $\beta^{\text {SER9 }}$, 4EPB1 ${ }^{\text {THR3 } 3746}$ modulation. Kelly cells were seeded and $24 \mathrm{~h}$ later treated with DMSO only (V), DMSO and IGF1 (V+I) or with NVP-BEZ235, Torin 1 or ZSTK474 for the indicated time and concentrations. All inhibitor treated cells were stimulated with IGF1 (50ng/ml) 30 minutes prior to harvesting. AKT ${ }^{\text {SER473 }}$, GSK3 $\beta^{\text {SER9 }}$, 4EPB1 $1^{\mathrm{THR} 37 / 46} \mathrm{MYCN}^{\mathrm{THR} 58}$ and total AKT, GSK3 $\beta, 4 \mathrm{EPB} 1$ and MYCN were assessed via western blotting and GAPDH used as a loading control. H. Immunoblotting analyses of concentration dependent effects of NVP-BEZ235, ZSTK474 and Torin1 treatment on MYCN stability and PI3K/mTOR biomarker AKT ${ }^{\mathrm{SER} 473}$, GSK3 $\beta^{\mathrm{SER} 9}$ and 4EPB1 ${ }^{\mathrm{THR} 37 / 46}$ modulation. IMR5 (Left panel) and SKN-Be2C (Right panel) neuroblastoma cells were seeded and $24 \mathrm{~h}$ later treated with DMSO only (V), DMSO and IGF1 (V+I) or with NVP-BEZ235, Torin1 or ZSTK474 at the indicated doses. All inhibitor treated cells were stimulated with IGF1 $(50 \mathrm{ng} / \mathrm{ml}) 30$ minutes prior to harvesting. AKT ${ }^{\mathrm{SER} 473}$, GSK3 $\beta^{\text {SER9 }}$, 4EPB1 $1^{\text {THR37/46 }} \mathrm{MYCN}^{\text {THR58 }}$ and total AKT, GSK3 $\beta, 4 \mathrm{EPB} 1$ and MYCN were assessed via western blotting and GAPDH used as a loading control. 
neuroblastoma cell lines to $\mathrm{PI} 3 \mathrm{~K} / \mathrm{mTOR}$ inhibition is somewhat surprising, since these cells lack intrinsic mutations in the PI3K pathway members PTEN or PIK3CA. These mutations prime cells for response to PI3K pathway inhibitors and therefore provided the rationale for the initial use of these agents in clinical trials [50-52]. To examine whether MYCN expressing neuroblastoma cells exhibit similar sensitivity to cells harboring intrinsic PI3K pathway mutations we used NVP-BEZ235 to treat a range of adult cancer cell lines (PTEN or PIK3CA mutant, with varying expression levels of MYC [53-58]), together with pediatric cell lines (wildtype for PTEN and PIK3CA) but with varying expression levels of either MYC or MYCN (Figure 1F). We found that cell lines harboring no/intermediate expression of MYCN or with stabilized MYCN were significantly less sensitive to NVP-BEZ235 compared to both $M Y C$ and $M Y C N$-amplified cell lines $(P<0.0001)$. Therefore, expression of MYCN is a marker of sensitivity to NVPBEZ235 treatment in pediatric cell lines and confers sensitivity equivalent to that of adult cell lines mutated in $P T E N$ or PIK3CA. Taken together, the implication is that expression of MYCN is a marker of sensitivity to PI3K/ mTOR pathway inhibition in neuroblastoma cells.

Having identified selective sensitivity of MYCNdependent cells to treatment with PI3K/mTOR inhibitors, we examined whether this could be explained by an intrinsic difference in PI3K pathway activation in these cells. We used an electro-chemiluminescent assay that quantitates $\mathrm{PI} 3 \mathrm{~K} / \mathrm{mTOR}$ signaling intermediates $\left(\mathrm{AKT}^{\mathrm{SER} 473}, \mathrm{GSK} 3 \beta^{\mathrm{SER} 9}\right.$, p70S6K ${ }^{\mathrm{THR} 389}$ and RPS6 ${ }^{\mathrm{SER} 240 / 244}$ ) to compare $\mathrm{PI} 3 \mathrm{~K} / \mathrm{mTOR}$ pathway inhibition in SHEP cells with exogenous expression of either MYCN WT or MYCN T58/S62 protein mutated within the CPD domain. NVP-BEZ235 caused potent blockade of PI3K and mTOR pathways in both SHEP WT and SHEP T58/S62 cell lines (Figure 2A-2D). Therefore the variance in viability between SHEP WT and SHEP T58/S62 cells following treatment with NVP-BEZ235 is unlikely to be due to differential inhibition of PI3K/mTOR pathway activity.

\section{Degradation of MYCN protein correlates with blockade of mTOR, not PI3K activity}

We next sought to establish whether MYCNselective inhibition observed in cellular assays correlates with elimination of MYCN protein, and if so, which component of PI3K pathway blockade is required for efficacy. To establish a time- and concentration-dependent biomarker response in a native neuroblastoma cell line we treated Kelly ( $M Y C N$-amplified, high MYCN protein) cells with NVP-BEZ235 for 1, 3, 6 and $12 \mathrm{~h}$. Treatment led to a rapid ( $3 \mathrm{~h}$ ) and sustained $(12 \mathrm{~h}$ ) elimination of MYCN protein by NVP-BEZ235 and Torin1 accompanied by a decrease in phosphorylation of 4EBP1 $1^{\text {THR } 37 / 46}$ (regulated by
mTORC1) and $\mathrm{AKT}^{\mathrm{SER} 473}$ (regulated by mTORC2) (Figure 2E, 2F). Compared to NVP-BE235 and Torin1, there was no significant degradation of MYCN with ZSTK474 treatment, despite evidence of PI3K pathway inhibition indicated by a decrease in $\mathrm{AKT}^{\mathrm{SER} 473}$ and GSK3$\beta^{\text {SER9 }}$ phosphorylation (Figure 2G). We confirmed these observations in two other $M Y C N$-amplified neuroblastoma cell lines, IMR5 and SKN-Be2C, which showed similar patterns in sensitivity and biomarker modulation with all three drug treatments (Figure $2 \mathrm{H}$ ). Furthermore, we treated the Kelly cell line at 2, 5 and $10 \mu \mathrm{M}$ with ZSTK474, which at higher concentrations can be a weak inhibitor of mTOR [59], and observed destabilization of MYCN, but only where mTOR activity was modulated (as measured through inhibition of both 4EBP1 $1^{\text {THR37/46 }}$ and RPS6 $6^{\text {SER240/244 }}$ (Figure 3A). Additionally, following cycloheximide treatment, the half-life of MYCN was shortened by NVPBEZ235 and Torin1 but not by ZSTK474 (Figure 3B). Taken together, these data imply that the ability of PI3K/ mTOR pathway inhibitors to eliminate MYCN protein correlates with effective targeting of both mTORC1 and mTORC2 activity.

\section{Blockade of mTOR stimulates proteasomal degradation of MYCN protein}

We next assessed whether the ability of mTORkinase inhibitors to eliminate MYCN exhibited evidence of dependence on the ubiquitin-ligase, proteasome degradation pathway. Treatment with the proteasome inhibitor MG132 resulted in accumulation of phosphorylated MYCN and reversed the ability of NVPBEZ235 to degrade MYCN protein (Figure 3C). NVPBEZ235 efficiently and rapidly eliminated exogenously expressed MYCN-WT protein in SHEP WT cells (Figure $3 \mathrm{D})$, an effect that was completely blocked by mutation of the CPD-domain T58 and S62 phosphorylation sites, despite evidence of excellent mTOR/PI3K pathway inhibition (Figure 3E). This suggests that the ability of $\mathrm{PI} 3 \mathrm{~K} / \mathrm{mTOR}$ pathway inhibitors to eliminate $\mathrm{MYCN}$ is mediated by phosphorylation of the N-terminal FBW7 target CPD domain, since mutation of phosphorylation sites within the CPD completely reverses the ability of these drugs to degrade MYCN (compare Figure 3D, 3E). We therefore concluded that the elimination of MYCN protein caused by $\mathrm{mTOR} / \mathrm{PI} 3 \mathrm{~K}$ pathway blockade is at least in part mediated through phosphorylation of $\mathrm{MYCN}$ T58/S62 phospho-residues.

\section{PI3K activity is not required for maintenance of cellular MYCN levels}

Our results indicate that $\mathrm{PI} 3 \mathrm{~K}$ inhibitors with weak activity against mTOR fail to target MYCN protein, implying that activity of the PI3K complex may not 


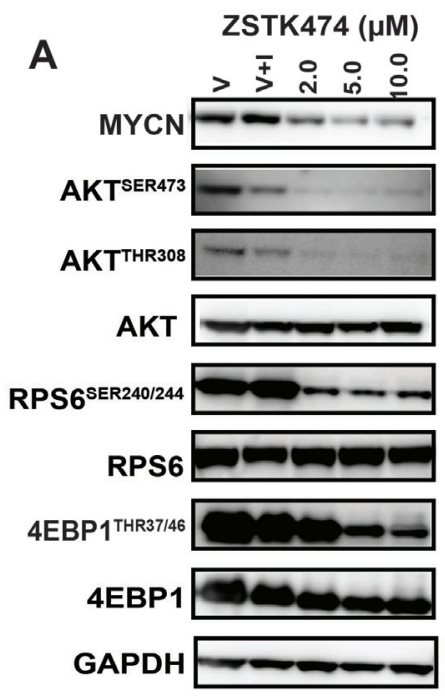

B

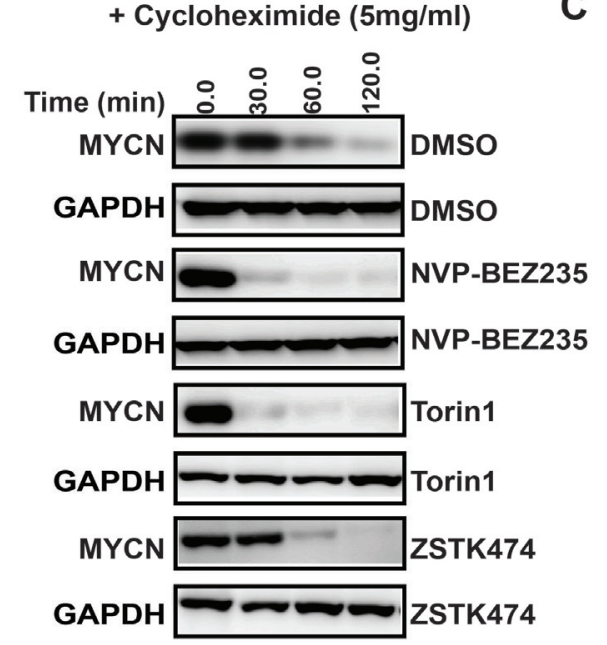

C

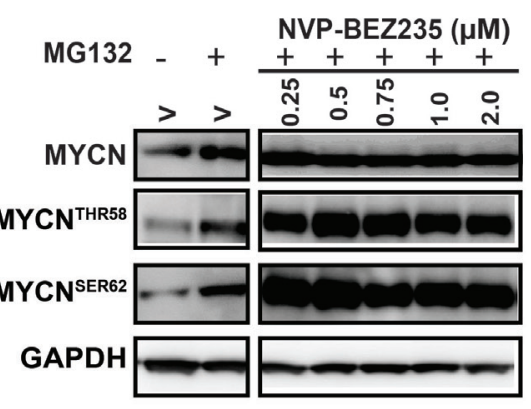

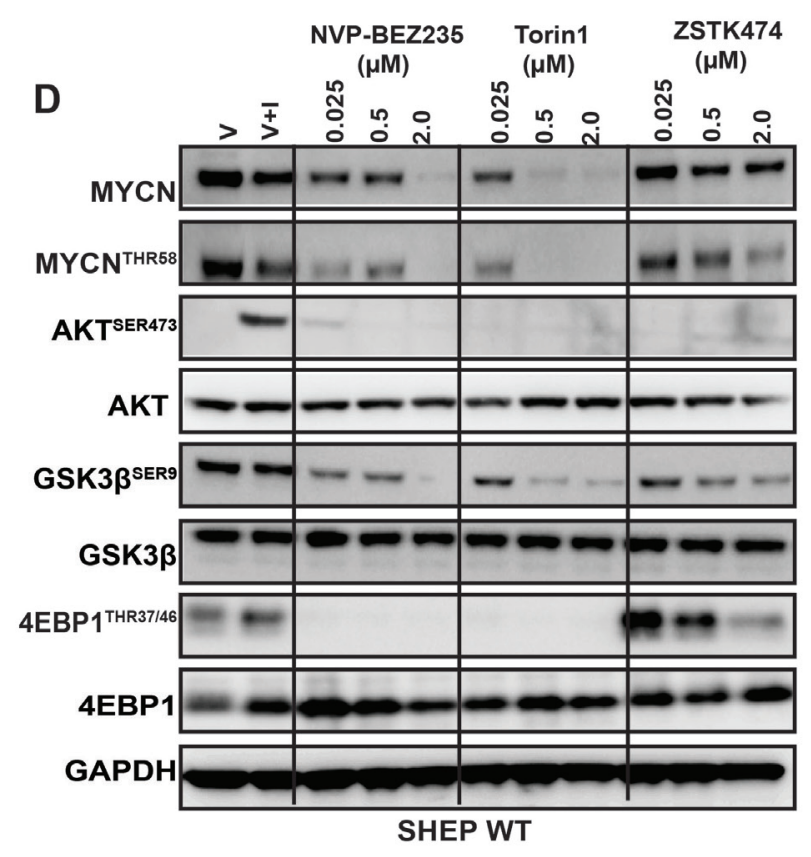

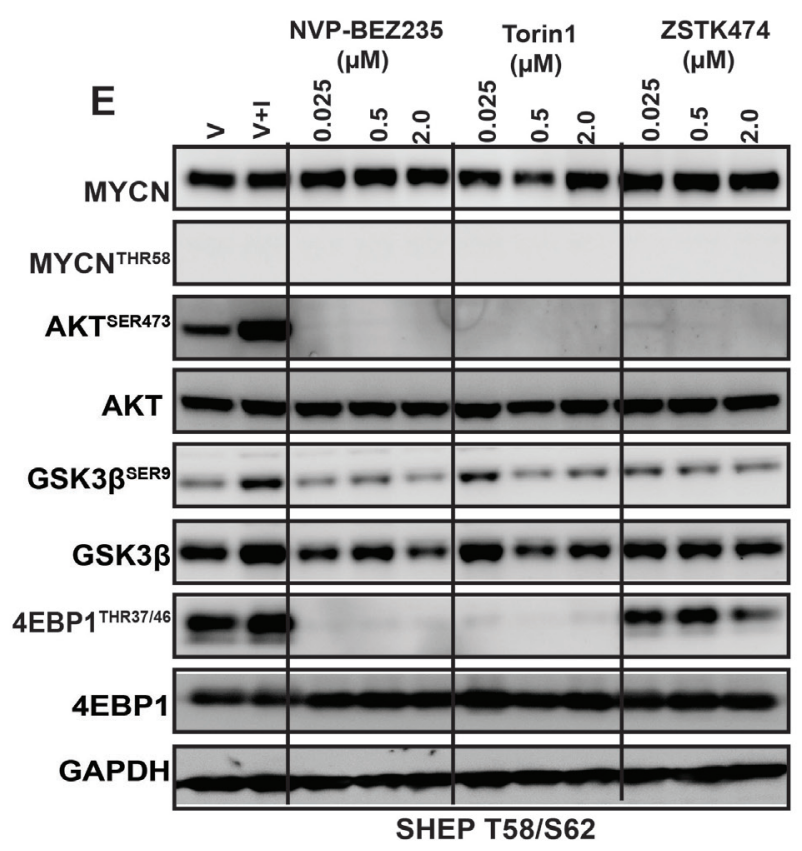

Figure 3: Inhibition of PI3K/mTOR signaling destabilizes MYCN. A. Depletion of MYCN following treatment with high concentrations of ZSTK 474, as measured by western blot analysis of AKT ${ }^{\mathrm{SER} 473}$, GSK3 $\beta^{\mathrm{SER} 9}, 4 \mathrm{EPB} 1^{\mathrm{THR} 37 / 46}$, RPS6 ${ }^{\text {SER240/244 }}$ and MYCN. Kelly cells were treated with DMSO (V), DMSO and IGF1 (V+I) or with ZSTK474, at the indicated concentration. All treated cells were stimulated with IGF1 $(50 \mathrm{ng} / \mathrm{ml}) 30$ minutes prior to harvesting. Total AKT, RPS6 and 4EPB1 were used as controls for each corresponding phosphospecific antibody and GAPDH used as a loading control. B. Treatment of Kelly neuroblastoma cells with $1 \mathrm{XGI}_{50}$ concentration of NVPBEZ235, Torin1 or ZSTK474 shortens the half-life of MYCN. Kelly neuroblastoma cells were treated with DMSO, NVP-BEZ235, Torin1 or ZSTK 474 for $2 \mathrm{~h}$ before the addition of cycloheximide $(5 \mu \mathrm{M})$ for $1 \mathrm{~h}$ to block translation of MYCN. Total MYCN protein expression was assessed by western blotting, and GAPDH used as a loading control. C. Hyper-phosphorylation of T58/S62 phosphoresidues of MYCN is driven by PI3K/mTOR inhibition. Kelly neuroblastoma cells were treated with DMSO (V), DMSO and the proteasomal inhibitor MG-132, or with NVP-BEZ235 in the presence of MG132 for $3 \mathrm{~h}$. Total, S62 and T58 pools of MYCN protein were assessed via western blot and GAPDH used as a loading control. D. Concentration dependent effects of NVP-BEZ235, Torin1 and ZSTK474 treatment on PI3K/mTOR pathway biomarkers AKT ${ }^{\mathrm{SER} 473}$, GSK3 $3 \beta^{\mathrm{SER} 9}$, 4EPB1 ${ }^{\mathrm{THR} 37 / 46}$ and MYCN stability in SHEP WT and (E) SHEP T58/S62 neuroblastoma cells. SHEP WT and SHEP T58/S62 cells were treated with DMSO (V), DMSO and IGF1 (V+I) or with NVP-BEZ235, Torin1 and ZSTK474 for $3 \mathrm{~h}$. All treated cells were stimulated with IGF1 (50ng/ml) 30 minutes prior to harvesting. Total AKT, GSK3 $\beta$, and 4EPB1 were used as controls for each corresponding phospho-specific antibody and GAPDH was used as a loading control. 
play a major role in stabilization of MYCN protein in neuroblastoma cells. To mechanistically address this possibility, we silenced p110 $\alpha$-PI3K expression in short- and long-term assays using siRNA and shRNA, respectively. Elimination of $\mathrm{p} 110 \alpha$ activity blocked phosphorylation of AKT but failed to reduce cellular MYCN protein levels (Figure 4A, 4B) or alter cell proliferation (Figure 4C). In addition, the ability of NVP-BEZ235 to stimulate MYCN degradation in these cells (immunoblot Figure 4D, 4E) or their sensitivity to treatment with NVP-BEZ235 $\left(\mathrm{GI}_{50}\right.$, as measured by 72 h SRB cytotoxicity assay, Figure 4F) was not altered by p110 $\alpha$ knockdown, whereas sensitivity to treatment with
ZSTK474 was significantly (6-fold) reduced (Figure 4G). This implies that the ability of combined PI3K/mTOR inhibitors to degrade MYCN protein is not dependent on intact $\mathrm{p} 110 \beta$ function, and furthermore that maintenance of MYCN protein levels in these cells largely proceeds through mTOR-dependent mechanisms.

\section{Elimination of $\mathrm{MYCN}$ protein requires concurrent inhibition of mTORC1 and mTORC2}

Although NVP-BEZ235 and Torin1, both ATPcompetitive and potent inhibitors of $\mathrm{PI} 3 \mathrm{~K} / \mathrm{mTOR}$ and
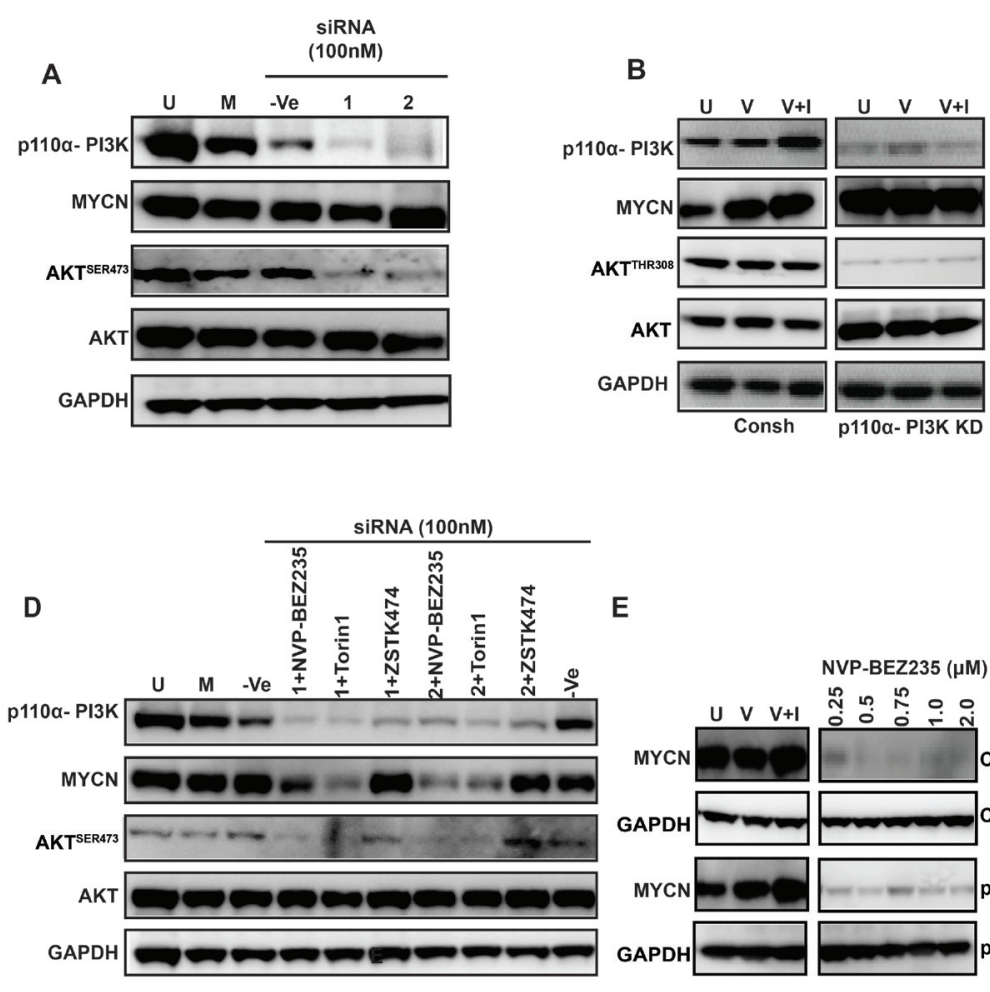

E

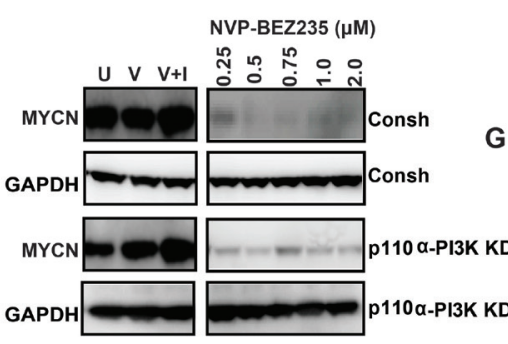

(1)
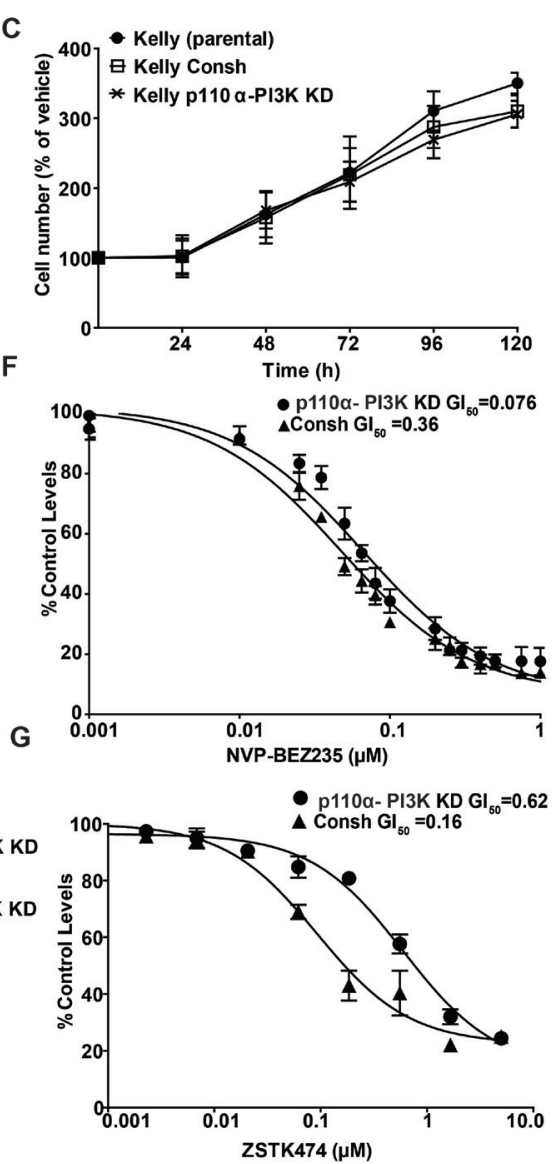

Figure 4: Role of the p110a-PI3K complex in MYCN stabilization. Knockdown of p110 alpha PI3K with siRNA does not modulate MYCN levels in Kelly $M Y C N$-amplified cells. A. Kelly neuroblastoma cells were transiently transfected with $100 \mathrm{nM}$ nontargeting (-Ve control) siRNA, or with 100nM of 2 single siRNA targeting P110 $\alpha$ - PI3K. Cells were harvested $96 \mathrm{~h}$ post siRNA treatment and P110 $\alpha$ - PI3K, AKT ${ }^{\mathrm{SER} 473}$ and MYCN protein levels were assessed via western blotting. B. Kelly neuroblastoma cells were stably transduced with control shRNA viral particles (Consh, left panel) or viral particles containing P110 $\alpha$ - PI3K coding shRNA (Right panel) and PI3K-P110 $\alpha, \mathrm{AKT}^{\mathrm{SER} 473}$ and MYCN protein levels assessed via western blotting. C. Kelly neuroblastoma cells were stably transduced with control shRNA viral particles or viral particles containing P110 $\alpha$ - PI3K coding shRNA and cell viability determined by SRB Kelly and Kelly CONSH shRNA neuroblastoma cell lines were used as controls. Values represent the averages of three independent assays. Error bars; standard deviation. D. Knockdown of p110 $\alpha$-PI3K does not affect MYCN destabilization induced by NVP-BEZ235 and Torin1. Kelly neuroblastoma cells were transiently transfected with P110 alpha PI3K targeting siRNA and at $3 \mathrm{~h}$ pre-harvest treated with NVP-BEZ235 $(500 \mathrm{nM})$, Torin1 $(500 \mathrm{nM})$ or ZSTK474 $(2 \mu \mathrm{M})$. Cells were harvested $96 \mathrm{~h}$ post siRNA treatment and P110 $\alpha$ - PI3K, AKT ${ }^{\text {SER } 473}$ and MYCN protein levels were assessed via western blotting. E. Western blot analysis of Kelly Consh and Kelly PI3K-P110 $\alpha$ shRNA cell lines treated with NVP-BEZ235 for 3 h. F., G. GI ${ }_{50}$ s as determined by trypan blue exclusion method in Kelly Consh and Kelly PI3K-P110 $\alpha$ shRNA cell lines treated for $72 \mathrm{~h}$ with NVP-BEZ235 or ZSTK474. Mean $\mathrm{GI}_{50}$ and standard error from three independent assays are shown. 
mTORC1/mTORC2 respectively, most effectively targeted MYCN in our studies, incomplete (rapalogue) inhibitors of mTOR have been more commonly used in the clinical setting. To establish if incomplete inhibition of mTORC1 alone could be effective in destabilizing MYCN we used rapamycin at a low concentration, known to block mTORC1 but not mTORC2 [60]. We were only able to observe MYCN degradation using rapamycin at $10-20 \mu \mathrm{M}$, a concentration at which total blockade of both mTORC1 (as measured by p4EBP $1^{\mathrm{THR} 37 / 46}$ ) and mTORC2 (as measured by AKT ${ }^{\text {SER } 473}$ ) occurs (Figure 5A). Similarly, the PI3K inhibitor ZSTK474 was only active against MYCN at high concentrations coinciding with inhibition of both

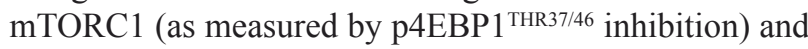
mTORC2 (as measured by AKT ${ }^{\mathrm{SER} 473}$ inhibition, Figure 3A). Furthermore, transient suppression of mTOR using siRNAs to target mTORC1 (RAPTOR) or mTORC2 (RICTOR) in Kelly cells partially reduced MYCN levels and targeting of mTOR kinase completely eliminated MYCN (Figure 5B, S2A-C), leading to rapid cell- killing (Figure 5C). Taken together these data imply that mTOR kinase plays a prominent role in the maintenance of MYCN stability and that complete blockade of both mTORC1 and mTORC2 is required to efficiently stimulate degradation of MYCN.

\section{The mTOR complex modulates GSK3 $\beta$ activity and regulates MYCN protein degradation}

The beta isoform of glycogen synthase kinase $(\mathrm{GSK} 3 \beta)$ is a $\mathrm{PI} 3 \mathrm{~K} / \mathrm{mTOR}$ pathway component and direct target of AKT that alters phosphorylation of MYC oncoproteins at the CPD. Phosphorylation of the CPD mediates complex formation between E3 ligases and MYC proteins, driving their degradation within the proteasome [61]. Activity of the mTORC2 (RICTOR/ mTOR) complex specifically stimulates $\mathrm{AKT}^{\mathrm{SER} 473}$ phosphorylation [62]. High levels of mTORC2 activity lead to inactivation of GSK3 $\beta$ (preventing phosphorylation of MYCN and proteasomal degradation). In our hands,
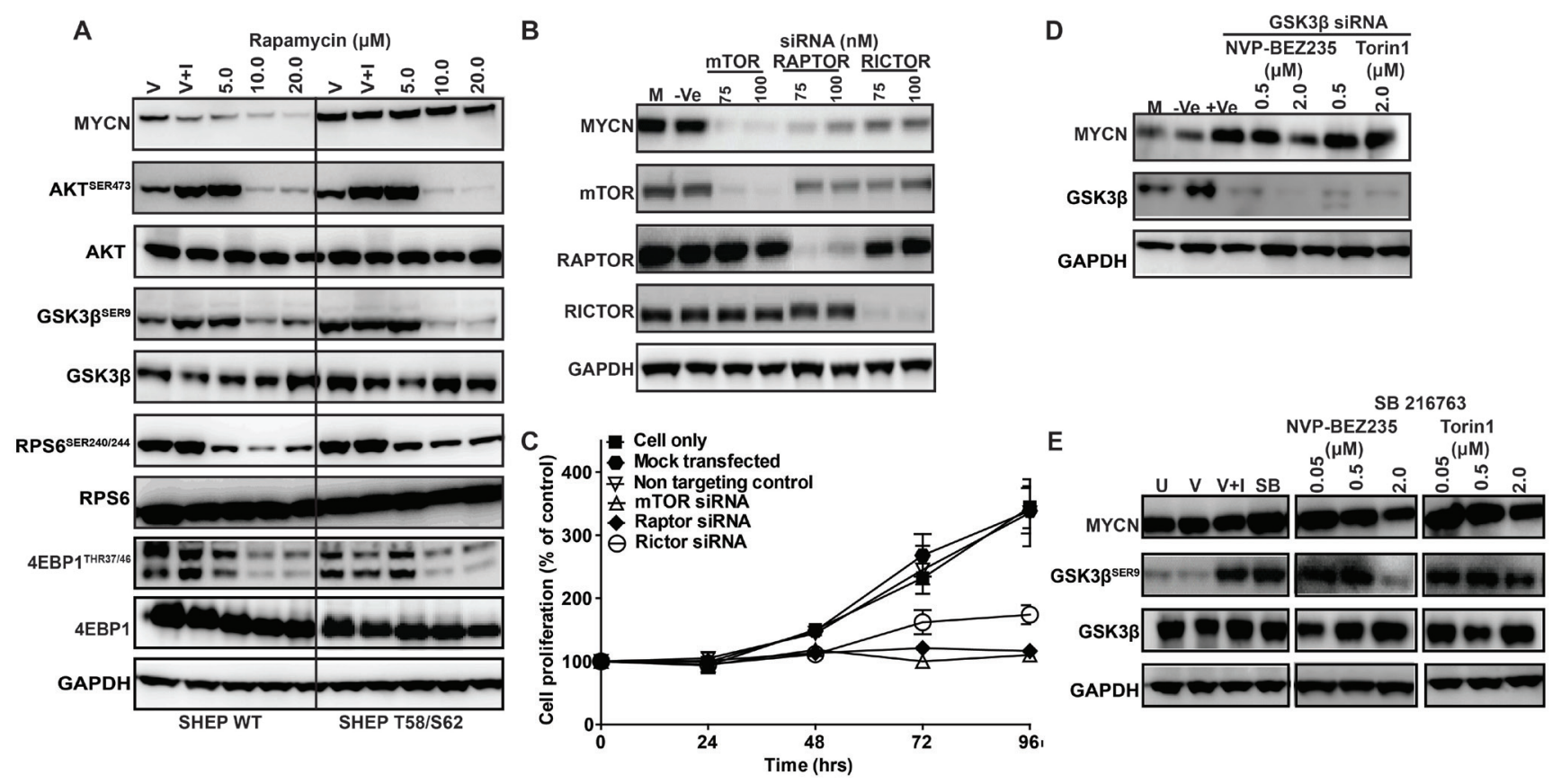

Figure 5: Role of mTOR and GSK3 in MYCN stabilization. Impact of mTOR, RAPTOR and RICTOR knockdown on Kelly neuroblastoma cell growth and MYCN degradation. A. Western blot analysis of AKT ${ }^{\mathrm{SER} 473}$, GSK3 $\beta^{\mathrm{SER} 9}, 4 \mathrm{EPB} 1^{\mathrm{THR} 37 / 46}$, RPS6 ${ }^{\mathrm{SER} 240 / 244}$ and MYCN levels after rapamycin treatment. SHEP WT and SHEP T58/S62 neuroblastoma cells were treated for $3 \mathrm{~h}$ with DMSO (V), with DMSO and IGF1 (V+I) or with rapamycin. Total AKT, GSK3 $\beta$, S6 and 4EPB1 antibodies were used as controls for each corresponding phospho-specific antibody and GAPDH was used as a loading control. B. Kelly neuroblastoma cells were transiently transfected with $75 \mathrm{nM}$ and 100nM of mTOR, RAPTOR, RICTOR or non-targeting (Ve) siRNA and mTOR, RAPTOR, RICTOR and MYCN levels examined by western blot. C. Cell viability was determined by SRB assay. D. GSK3 $\beta$ inhibition stabilizes MYCN. Kelly neuroblastoma cells were transiently transfected with either a non-targeting (-Ve) or GSK3 $\beta$ targeting siRNA and at $3 \mathrm{~h}$ pre-harvest treated with NVP-BEZ235 $(500 \mathrm{nM})$ or Torin $1(500 \mathrm{nM})$. Cells were harvested $96 \mathrm{~h}$ post siRNA treatment and GSK3 $\beta$ and MYCN protein levels assessed by western blot. E. Chemical inhibition of GSK3 $\beta$ in Kelly cells. Kelly cells were untreated (U), treated with DMSO (V), with DMSO and IGF1 $(\mathrm{V}+\mathrm{I})$, with GSK3 $\beta$ inhibitor SB216763 (SB) or with the indicated concentration of NVP-BEZ235 or Torin1 in the presence of SB216763. GSK3 $\beta^{\text {SER9, }}$ total GSK3 $\beta$ and MYCN protein levels were assessed by western blot. GAPDH was used as a loading control. See also Figure $\mathrm{S} 2$. 
the ability of PI3K/mTOR pathway inhibitors (including NVP-BEZ235 and Torin1) to efficiently target MYCN required intact GSK3 $\beta$ activity (Figures 2 and 3 ). To test this observation, we knocked-out GSK $3 \beta$ with siRNA. Suppression of GSK3 $\beta$ increased stable intracellular levels of MYCN (Figure S2D, E) and both genetic (Figure 5D) and pharmacologic (Figure 5E) inhibition of GSK3 $\beta$ abrogated the ability of NVP-BEZ235, Torin1 (and other PI3K or mTOR inhibitors, data not shown) to degrade MYCN. These data establish that the mTOR complex, and mTORC2 in particular, plays a critical role in maintenance of cellular MYCN levels, requiring intact function of GSK3 $\beta$, the activity of which appears to be rate-limiting for the ability of PI3K/mTOR inhibitors to stimulate
MYCN degradation.

In vivo inhibition of mTOR-kinase targets MYCN-driven tumors in animal models

A stringent test of whether MYCN destabilization is a viable therapeutic strategy for MYCN-driven cancers is to establish whether murine tumors genetically-engineered to overexpress $\mathrm{MYCN}$, together with primary human neuroblastoma tissue amplified for $M Y C N$, are targeted in vivo. We assessed whether ZSTK474 and NVP-BEZ235 could inhibit tumor progression using a transgenic model of neuroblastoma (TH-MYCN), in which tumor formation
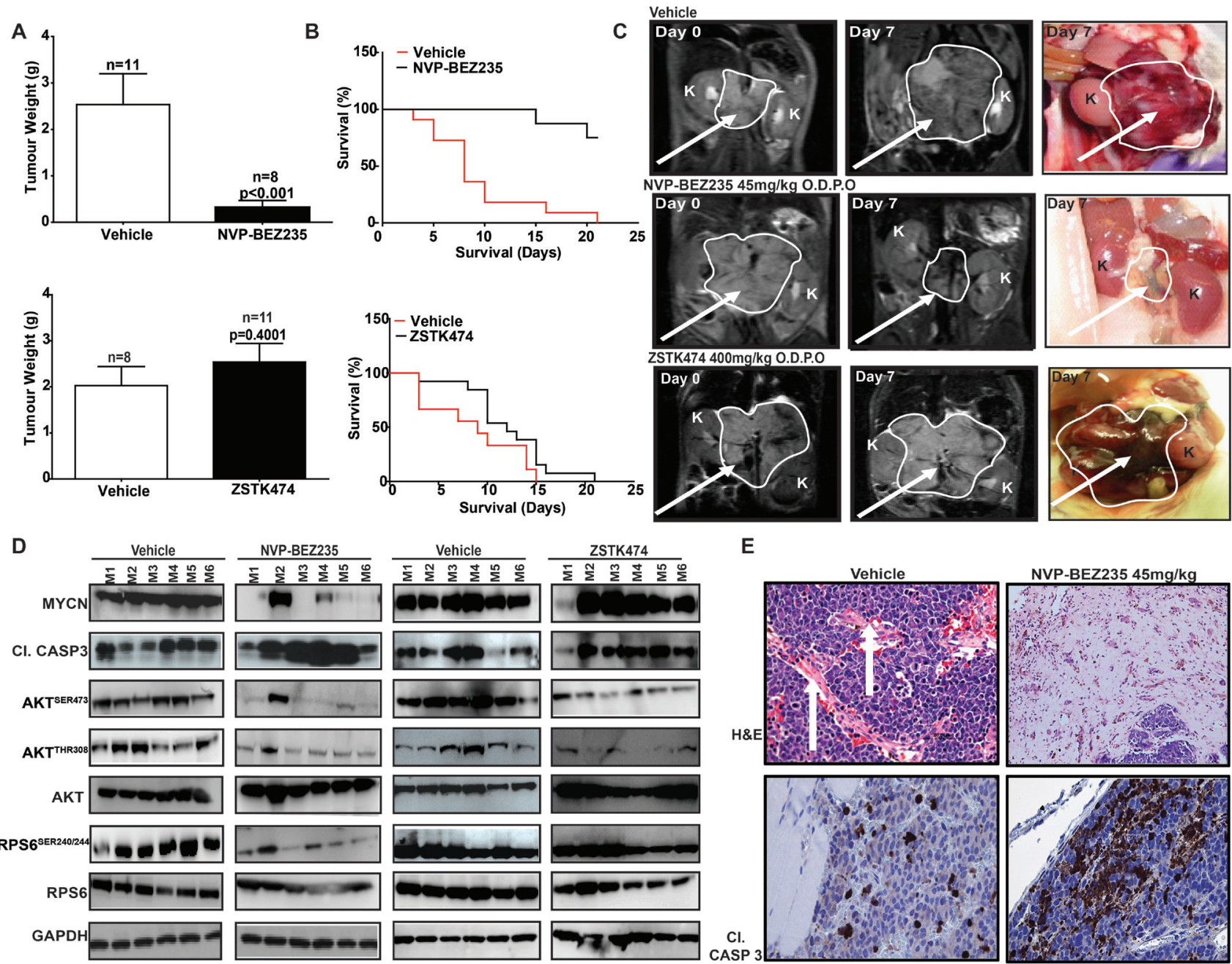

$E$
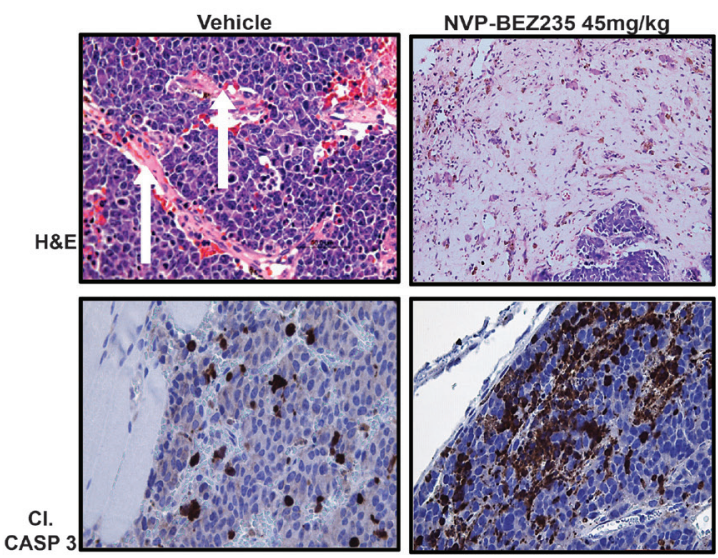

Figure 6: PI3K/mTOR pathway inhibition restricts the growth of MYCN-driven transgenic tumors. Tumor-bearing animals transgenic for TH-MYCN were treated daily using oral gavage with $45 \mathrm{mg} / \mathrm{kg}$ NVP-BEZ235 $(n=8)$, NVP-BEZ235 vehicle $(n=11)$, $400 \mathrm{mg} / \mathrm{kg}$ ZSTK474 $(n=11)$ or ZSTK474 vehicle $(n=8)$. A. Average weight $(\mathrm{g})$ of resected tumors relative to vehicle for NVP-BEZ235 (top panel) and ZSTK474 (lower panel). B. Kaplan-Meier 21 day survival curves for NVP-BEZ235 (top panel) or ZSTK474 (bottom panel). C. Representative $\mathrm{T}_{2}$-weighted MRI images and gross pathology of vehicle NVP-BEZ235 or ZSTK474 treated tumors at indicated times (arrow = tumor, K, kidney). D. Western blot analysis of tumors treated with NVP-BEZ235, ZSTK474 or respective vehicles. M1M6 indicates tumor samples from cohorts of 6 individual animals, treated with either NVP-BEZ235, ZSTK474 or their respective vehicle controls. E. Tumor pathology (Hematoxylin \& Eosin) and immunochemical staining (cl. Casp. 3) for vehicle (left panels) and NVPBEZ235 treated (right panels) tumors. (White arrows = vascularization). See also Figure S3. 
is driven by tissue-specific overexpression of MYCN within murine neural crest [63]. Animals were treated for 21 days with $45 \mathrm{mg} / \mathrm{kg} /$ day NVP-BEZ235 or $400 \mathrm{mg} / \mathrm{kg}$ ZSTK474 [59, 64]. Both treatments were well tolerated (Figure S3A-C). Intra-tumoral levels of NVP-BEZ235 and ZSTK474 were verified by mass spectroscopy and the drugs were present in tumor tissue above concentrations required for inhibition of their respective targets (Figure $\mathrm{S} 3 \mathrm{D})$. Tumor mass response following necropsy (Figure 6A) and extension of survival (Figure 6B) were assessed as trial endpoints, and tumor regression was monitored in vivo using serial magnetic resonance imaging (MRI) (Figure 6C). Importantly, NVP-BEZ235 induced complete responses (by RECIST criteria) in the majority of treated tumors, with volume and mass reduction $>75 \%$ (Figure 6A) translating to extension of survival (Figure 6B). Conversely, ZSTK474 lacked any anti-tumor activity (compare Figure 6A, 6B upper and lower panels) despite achieving intra-tumoral concentrations sufficient for inhibition of AKT phosphorylation (Figure 6D). In responding tumors, NVP-BEZ235 blocked both PI3K $\left(\mathrm{AKT}^{\mathrm{SER} 473 / 308}\right)$ and mTOR signaling (RPS6 $\left.{ }^{\mathrm{SER} 240 / 244}\right)$, resulting in almost complete elimination of MYCN protein (Figure 6D), and induction of apoptosis (cleavage of caspase 3 ) on immunoblot and by immunohistochemistry (Figure 6D, 6E). Interestingly, two mice in the NVP-

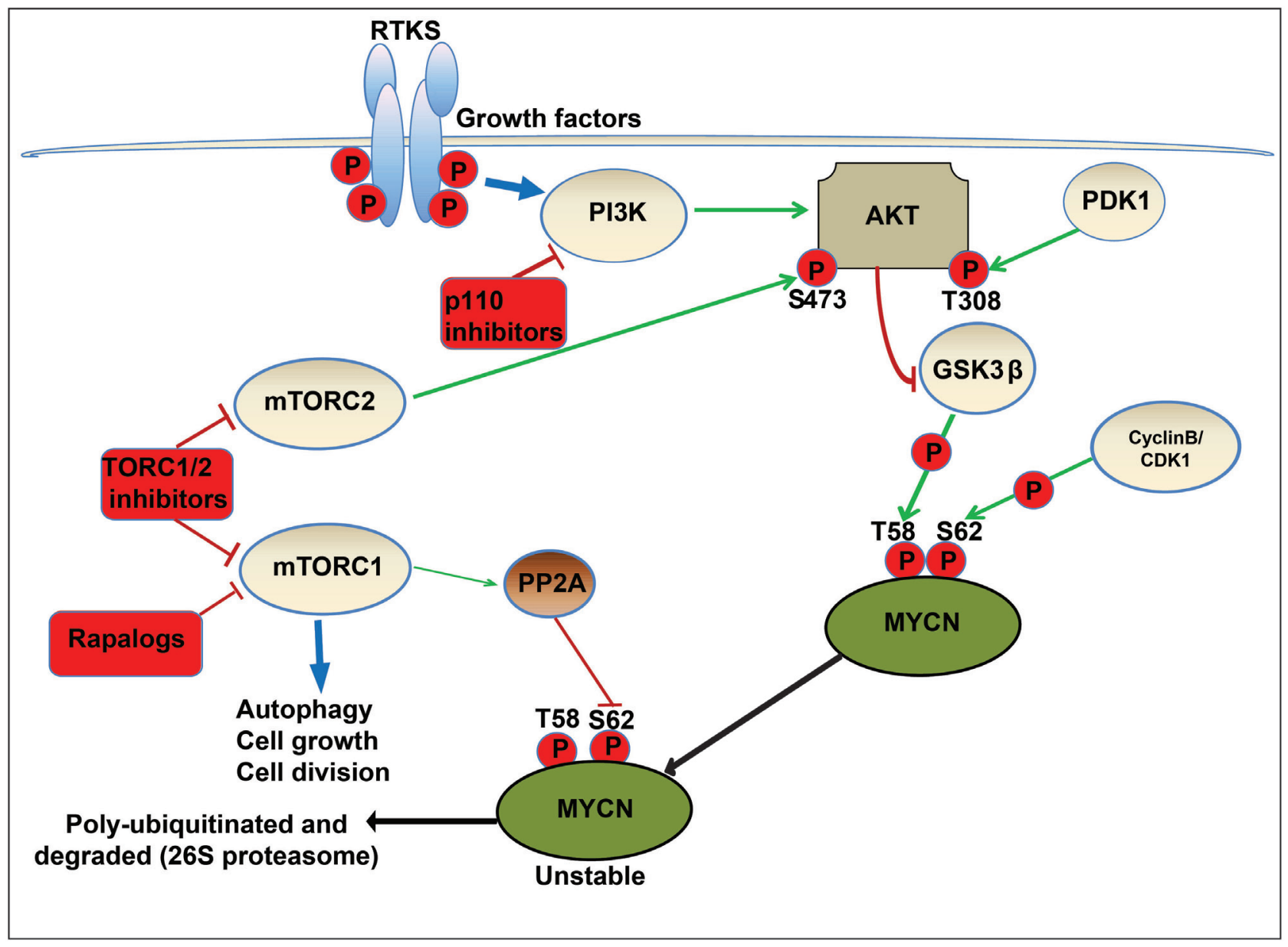

Figure 7: Schematic model of regulatory pathways involved in MYCN turnover. In neuronal precursor cells, MYCN is initially phosphorylated at serine 62 (S62) by cyclin-dependent kinase 1/CyclinB. This acts as a priming phosphorylation that permits binding of GSK3 $\beta$, PIN1 and PP2A. Subsequently, active GSK3 $\beta$ phosphorylates MYCN at threonine 58 (T58), yielding doubly phosphorylated MYCN. In a MYCN driven cancer cell model, RTKs activate PI3K, and the downstream target AKT, localising it to the membrane and allowing phosphorylation and activation of AKT at threonine 308 (T308) by PDK1. Active AKT phosphorylates and inactivates GSK3 $\beta$, blocking phosphorylation of MYCN therefore preventing proteasomal degradation. The mTORC1 complex (mTOR-raptor) also directly phosphorylates and inhibits PP2A, enabling the accumulation of S62 phosphorylated and active MYCN. In addition, the mTORC2 complex (mTOR-RICTOR) phosphorylates and further activates AKT at serine 473 (S473). NVP-BEZ235 destabilizes MYCN by blocking activation of AKT (via inhibition of TORC1 and TORC2 complexes) and reactivating GSK3 $\beta$, permitting phosphorylation of MYCN (T58) and initiating proteasomal degradation. 
BEZ235 treatment cohort experienced incomplete responses with partial tumor regression and progression, respectively (T2 and T4, Figure S3A, B), and in each case inhibition of PI3K (AKT ${ }^{\mathrm{SER} 473 / 308}$ ) and mTOR (RPS6 $^{\text {SER240/244 }}$ ) was incomplete, with only partial reduction in MYCN levels (M2 and M4, Figure 6D). Consistent with the idea that complete blockade of $\mathrm{mTOR}$ is a requirement for therapeutic efficacy of PI3K/mTOR pathway inhibitors in the setting of MYCN-dependency, ZSTK474 exhibited little activity against mTOR signaling (RPS6 ${ }^{\text {SER240/244 }}$ ) and demonstrated no therapeutic benefit in this MYCN-driven model (Figure 6D).

To further confirm the efficacy of NVP-BEZ235 as a therapeutic for $M Y C N$-amplified neuroblastoma in patients, we performed an in vivo preclinical trial using a primary xenograft model in which tumor tissue from a patient (SFNB-08) with high-grade, $M Y C N$-amplified neuroblastoma was implanted orthotopically into the kidney capsule. Animals were treated with NVP-BEZ235 or vehicle for 14 days at $45 \mathrm{mg} / \mathrm{kg}$. Measurement of both tumor volume and weight again showed a significant decrease in tumor burden in NVP-BEZ235-treated animals in comparison to vehicle (Figure S4A, B). Immunoblotting of tumor tissue confirmed that NVP-BEZ235 blocked PI3K (AKT ${ }^{\text {SER } 473 / 308}$, GSK3 $\beta^{\text {SER9 }}$ ) and mTOR signaling (RPS6 $^{\mathrm{SER} 240 / 244}$, 4EBP1 $1^{\mathrm{THR} 37 / 46}$ ) coincident with downregulation of intra-tumoral MYCN protein (Figure S4C). In addition, Ki67 staining showed a significant reduction in cellular proliferation (Figure S4D). Taken together, these data illustrate the potency of the PI3K/mTOR inhibitor NVP-BEZ235 against two different MYCN-driven tumor models, establish that the mechanism of action relates to elimination of MYCN protein, and highlight the potential for treatment of MYCN-driven malignancies in children using clinically available inhibitors of mTOR.

\section{DISCUSSION}

Oncogenic expression of MYC proteins is common in adult cancers and also occurs in neuroblastoma [1, 2], medulloblastoma [8], rhabdomyosarcoma [7] and retinoblastoma [9], four common pediatric solid tumors that together account for a major fraction of death from relapsed cancer in children. In these conditions, aberrant expression of $\mathrm{MYCN}$ is associated with high-risk disease, poor clinical prognosis and death due to metastatic relapse (reviewed in [4]). The prominent role of MYC proteins in oncogenesis, and the fact that $\mathrm{MYCN}$ expression is restricted to tumor tissue in several pediatric malignancies with poor outcome, implies that MYCN is likely to be an important therapeutic target, presenting a unique opportunity for targeted molecular therapeutic intervention in pediatric cancer [4].

That particular cancers can be addicted to oncogenic signaling changes induced by aberrant MYC expression is well-established through the use of oncogene-regulated mouse models [63, 65-75]. In this setting, repetitive genetic inactivation of MYC causes regression of several malignancies without evidence of acquired genetic resistance, and with reversible toxicity to normal organs [5, 76-79]. Collectively, these data underpin the rationale for direct pharmacologic inhibition of MYC, however in practice this has been difficult. Given the prominent role of MYCN in the genesis of aggressive pediatric tumors, we sought to identify existing therapeutics that could be useful to target MYCN indirectly, using neuroblastoma as a paradigm of a pediatric tumor that exhibits both clinical and experimental evidence of dependence and addiction to MYCN overexpression.

MYC-family proteins are oncogenically stabilized by altered phosphorylation within an n-terminal conserved phosphodegron domain (CPD). Binding to the CPD is a function of the ubiquitin ligases (FBW7, HUWE1) and is required for initiation of proteasomal degradation. Phosphorylation of conserved T58 and S62 residues within the CPD is regulated by CDK1 (a MAPK target), and by the PI3K/AKT-regulated targets GSK3 $\beta$ and mTOR, respectively (Figure 7). Based on knowledge of this mechanism, individual compounds which modulate GSK3 $\beta$ and target MYCN have been reported [13, 37, 80]. However, a comprehensive understanding of how PI3K/ mTOR inhibitors target MYC proteins and a rationale for the selection of compounds likely to be clinically active against MYC-driven cancers is lacking. Given that pan$\mathrm{PI} 3 \mathrm{~K}$, dual PI3K/mTOR and TORC1/2 kinase inhibitors are progressing through early pediatric clinical evaluation, it is important to clearly define the patient population most likely to benefit from treatment and to prioritize inhibitors for clinical trials $[52,81]$. To date, none of these compounds have been ranked for their potential to inhibit MYC/MYCN in pediatric cancers, although several drugs (rapamycin and the later generation rapalogue inhibitors temsirolimus and ridaforolimus) have been evaluated in the setting of relapsed solid tumors without a hypothesis relating to $\mathrm{MYC}$ or MYCN expression.

A practical cell-based approach to rank compounds with the ability to destabilize MYC protein would provide a valuable roadmap to prioritize drugs for early phase trials. We therefore designed a chemical-genetic screen using isogenic (SHEP neuroblastoma) cells varying in expression of wild-type or CPD-mutated, stabilized MYCN, and we assessed selective sensitivity to treatment with a library of 228 drugs or chemical probes [82, 83]. No statistically significant difference in proliferation rate was observed between SHEP cells expressing wildtype or stabilized MYCN in this screen, excluding the possibility that selective sensitivity related to changes in basal proliferation rate. However, we cannot discount the possibility that additional mechanisms associated with MYCN overexpression, and unrelated to stabilization of MYCN protein, could account for drug sensitivity in this screen. For example, MYC protein overexpression 
has been linked to defects in apoptosis [84], altered DNA damage repair responses [85], changes in chromosomal stability [86] and cell metabolism [87]. Many of these factors are the likely basis for previously described synthetic lethal relationships associated with MYCN expression. Nevertheless, we were able to identify several classes of small molecule inhibitor that selectively target cells expressing MYCN protein, and as proof-of-principle we characterized one class of compound that demonstrated considerable efficacy in two independent pre-clinical models of MYCN-driven neuroblastoma. We illustrate the feasibility of this mechanistic and translational approach in identifying regulators of MYCN stability, focusing on $\mathrm{PI} 3 \mathrm{~K} / \mathrm{mTOR}$ and mTOR inhibitors as an effective class and mitigating the risk of off-target effects by using multiple inhibitors across the pathway, as well as siRNA silencing of pathway components. We focus on NVP-BEZ235 as an example of a selective PI3K/mTOR inhibitor that is able to suppress MYCN protein and induce growth-inhibitory effects in MYCN expressing cells, although several candidate inhibitors are now in clinical evaluation. From our data, the most effective inhibitors induce total blockade of both mTORC1 and mTORC2, which appear to regulate downstream processes that are key in controlling MYCN protein levels and cellular dependency on MYCN expression.

The basis for the relationship between MYCN expression and sensitivity to mTOR inhibition is unclear, but several possibilities are likely. In order to tolerate oncogenic overexpression of MYC, cancer cells must undergo a major remodeling of metabolic and translational pathways- both of which are regulated by mTOR [87]. Indeed, MYC has previously been shown to be involved in a feed-forward loop involving the translation machinery component eIF4F that links transcription and translation, regulating cell growth and protein synthesis [88, 89]. Uncoupling of this feed-forward loop via perturbations in expression of key proteins including those under the control of mTOR (such as 4EBP1) is a likely mechanism that fuels cancer cell growth and cellular addiction to MYC expression [16, 89-91]. Finally, neuroblastomas with high levels of MYCN expression exhibit defined metabolic deficiencies in glucose metabolism (Warburg physiology) and are polyamine-dependent under hypoxic conditions $[92,93]$. MYC directly interacts with HIF-1 linking altered cellular metabolism to tumorigenesis by regulating genes involved in the biogenesis of ribosomes, mitochondria, and regulation of glucose and glutamine metabolism [94, 95].

Advances in medicinal chemistry have delivered potent small-molecules to clinical use that have the ability to achieve effective in vivo blockade of major oncogenic signaling pathways through either direct targeting of oncoproteins or through synthetic lethal relationships exposed by oncogene expression [83]. The availability of multiple clinical inhibitors that target pathways of high relevance to cancer treatment mandates thorough mechanistic prioritization. Here we show that within the class of available inhibitors of $\mathrm{PI} 3 \mathrm{~K} / \mathrm{mTOR}$ pathway, compounds that selectively block mTORC1/mTORC2, such as the combined PI3K/mTOR inhibitor NVPBEZ235, efficiently target MYCN protein stability and cause in vivo regression of neuroblastoma, a MYCNdriven pediatric tumor. Selective inhibitors of PI3K do not exhibit this activity. This has important implications for planned trials of these compounds in pediatric cancer, since multiple PI3K, mTOR and dually targeted PI3K/ mTOR drugs are already in active clinical evaluation. The success of pediatric trials utilizing these agents will depend as much on careful selection of the appropriate agent as on the target patient population likely to benefit from treatment.

\section{MATERIALS AND METHODS}

\section{Cell lines and reagents}

Kelly, SH-SY5Y, SHEP, SK-N-SH, IMR32, SKNBe2C, IMR5 and SK-N-AS human neuroblastoma cell lines were obtained from the University of California at San Francisco Cell Culture Facility (San Francisco, CA) and from the American Type Culture Collection (Manassas, VA). Cells were grown in DMEM or RPMI containing 10\% fetal bovine serum (PAA "Gold"). In specified experiments, cells were serum starved in $0.2 \%$ FCS for $6 \mathrm{~h}$ before analysis and treated with recombinant human insulin-like growth factor-1 (IGF-1; Sigma) at $50 \mathrm{ng} / \mathrm{mL}$ for $30 \mathrm{~min}$ before harvesting. NVP-BEZ235 (Novartis), Torin1 (Nathaniel Gray), staurosporine (Alexis Biochemicals), ZSTK474 (Alexis Biochemicals), GSK3 $\beta$ inhibitor (Calbiochem), TGX221 (Selleck chemicals), PIK90 (Selleck chemicals) and Rapamycin (Selleck chemicals) were all prepared as a $10 \mathrm{mM}$ stock solution in $100 \%$ DMSO. Working solutions were prepared freshly by dilution in $100 \%$ DMSO prior addition to the cell media at a final concentration of $0.1 \%$ DMSO. SHEP cells were stably transfected with constructs wild-type or mutant for MYCN and appropriate clones were screened and selected essentially as described previously [37]. Cells were regularly screened for Mycoplasma using a PCRbased assay (VenorGem, Minerva Biolabs).

\section{In vitro proliferation and inhibitor treatment}

Cells were seeded in triplicate wells of 96-well flat bottom culture plates $\left(3-6 \times 10^{3}\right.$ per well) and allowed to attach for $24 \mathrm{~h}$ to ensure exponential growth at the time of treatment. Cells were then incubated for $72 \mathrm{~h}$ in the presence of increasing concentrations of indicated inhibitors. Cell viability and median-effect concentration 
affecting growth $\left(\mathrm{GI}_{50}\right)$ was determined using the SRB (Sulforhodamine B colorimetric assay) and $\mathrm{GI}_{50}$ values were derived as described previously [96]. Apoptosis was assessed by caspase cleavage. The activities of caspase-3 and -7 were measured by luminescence detection using the Caspase-Glo ${ }^{8}$ 3/7 assay kit (Promega, Inc.). The assay provides a luminogenic caspase- $3 / 7$ substrate in a reagent that when added to cells results in cell lysis, followed by caspase cleavage of the substrate and generation of a luminescent signal produced by luciferase. The assay was performed according to the manufacturer's instructions. The mean difference was calculated using Student's t-test. Values were standardized to the maximal effect of Staurosporine $(2 \mu \mathrm{M})$.

\section{Kinase inhibitor screen}

SHEP WT and SHEP T58/S62 were seeded in 384well plates for 48 hours before treatment with 40, 200 and $1000 \mathrm{nM}$ of 228 kinase inhibitors and chemical probes for 96 hours [82, 97-99]. Cell viability was determined using CellTiter-blue reagent (Promega, Inc.). The Z-factor was $>0.5$ for all plates analyzed. The data was plotted as a ratio of SHEP T58/S62:SHEP WT.

\section{Immunoblotting}

Inhibitor-treated cells were lysed and suspended in non-denaturing lysis buffer (Cell Signaling Technology, Danvers, MA) containing 1x concentrate protease and phosphatase inhibitor cocktail tablets (Roche, Lewes, UK). Samples were transferred to polyvinylidene difluoride membranes, which were incubated in a blocking buffer (5\% dried milk in TBS or 3\% ECL advance blocking reagent) and probed with primary antibody in blocking buffer overnight at $4{ }^{\circ} \mathrm{C}$. Proteins were detected with HRP conjugated secondary antibody (DAKO) and visualized with enhanced chemiluminescence reagents (GE Healthcare). Antibodies used were as follows: Rabbit anti MYCN polyclonal antibody (Santa Cruz Biotechnology, Santa Cruz, CA), mouse anti MYCN monoclonal antibody (Calbiochem, Merck KGaA, Darmstadt, Germany), rabbit anti-phospho MYCN (S54) polyclonal antibody (Bethyl Labs, Montgomery, TX), rabbit anti-phospho c-Myc (T58/ S62) polyclonal antibody (Cell Signaling Technologies, Danvers, MA), Rabbit and mouse antibodies specific for total and phosphorylated forms from CST: AKT (\#2965, \#9267, \#4058, \#9272, \#9271, \#4056), ribosomal protein S6 (\#2317, \#2211), P70S6K (\#9204, \#2708), 4EBP1 (\#9644, \#9459), GSK3ß (\#9323, \#9315), cleaved caspase-3 (\#9664), Raptor (\#2280), Rictor (\#2114), mTOR (\#2983) and GAPDH (\#2118). Phosphorylation of $\mathrm{AKT}^{\text {SER } 473}, \mathrm{GSK}^{\text {SER9 }}$, RPS6 ${ }^{\text {SER240/244 }}$ and P70S6K $\mathrm{K}^{\text {SER } 21 / 424}$ was also determined using an electrochemiluminescent immunoassay (MesoScale Discovery) as described previously [44].

\section{Transfection of Kelly neuroblastoma cells with siRNA}

MYCN, GSK3 $\beta$, mTOR, RAPTOR or RICTOR single or SMARTpool siRNA (Dharmacon) and PI3KP110 $\alpha$ single siRNA (Ambion) was introduced into the cells by complex formation with Lipofectamine 2000 lipid transfection reagent (Invitrogen) according to transfection recommendations of the manufacturer. Lentiviral packaging vectors pMD2.G ( $3 \mu \mathrm{g})$, pMDLg/pRRE $(5 \mu \mathrm{g})$, pRSV-REV $(2.5 \mu \mathrm{g})$ (Addgene) and the MYCN shRNA vector $(10 \mu \mathrm{g}$, TRCN0000020696, Sigma-Aldrich, UK) or

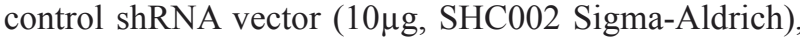
also in complex with lipofectamine, were transfected into the HEK293T packaging cell line seeded in $T 75 \mathrm{~cm}^{2}$ tissue culture flasks. Twenty-four hours after transfection, the culture media were replaced by fresh media corresponding to the cell line being transduced. After another $24 \mathrm{~h}$ of incubation, the lentiviral particle containing media were clarified by centrifugation and passed through a Millex HV $0.45 \mu \mathrm{m}$ PVDF filter (Millipore, Bedford, MA, USA). The viral titre was calculated using the HIV p24 ELISA (Cambridge Biosciences) and viral aliquots stored at -80oC. KELLY, SHEP WT and SHEP T58/S62 cells were transduced with lentivirus at a calculated multiplicity of infection (MOI) of 10 (assuming 50\% packaging efficiency) in the presence of polybrene $(4 \mu \mathrm{g} / \mathrm{ml})$. The following day the virus-containing media were replaced with normal growth media and $24 \mathrm{~h}$ later, knock down cells were selected using puromycin $(5 \mu \mathrm{g} / \mathrm{ml}$ continuous treatment for at least 1 week).

\section{In vivo transgenic experiments}

Transgenic TH-MYCN animals with palpable tumors (40-80 days old) were randomized and treated with $45 \mathrm{mg} /$ $\mathrm{kg}$ NVP-BEZ235, 400mg/kg ZSTK474, or vehicle. NVPBEZ235 and ZSTK474 were administered via oral gavage. To assess the pharmacokinetic and pharmacodynamic profiles of NVP-BEZ235, plasma and tumor samples were harvested at 1 hour and 6 hours following dosing. Mice were bled by cardiac puncture, and plasma samples were collected and frozen at $-20^{\circ} \mathrm{C}$ until analysis. Tumors were dissected, divided into 3 approximately equal pieces, and snap frozen in liquid nitrogen until analysis. For pharmacodynamic studies, tumors were homogenized using T-PER buffer ${ }^{\mathrm{TM}}$ (Thermo Scientific), 1x concentrates protease and phosphatase inhibitor cocktail tablets (Roche, Lewes, UK). Protein content was measured using Bradford reagent and samples were analyzed using immunoblotting as described previously. MRI was performed on a 7T Bruker horizontal bore microimaging system (Bruker Instruments, Ettlingen, Germany) using a $3 \mathrm{~cm}$ birdcage 
coil. Anatomical $\mathrm{T}_{2}$-weighted coronal images were acquired from twenty contiguous $1 \mathrm{~mm}$ thick slices through the mouse abdomen, from which tumor volumes were determined using segmentation from regions of interest drawn on each tumor-containing slice At necropsy, tumors were excised, measured, weighed, and snap frozen. Significance analysis was performed using the Student's $t$ test. Mice were monitored daily and tumor size was palpated and animal weight measured daily. Animals were treated in accordance with local and national animal welfare guidelines [100].

\section{In vivo orthotopic experiments}

A human $M Y C N$-amplified primary tumor designated SFNB-08 was obtained from a patient with high-grade neuroblastoma, previously treated with cyclophosphamide, topotecan, cisplatin, etoposide, doxorubicin, and vincristine. Tumor pieces $\left(4 \mathrm{~mm}^{3}\right)$ were implanted into the kidney capsule of nude mice. After 7 days, mice were treated with either vehicle PEG300 control or NVP-BEZ235 $(45 \mathrm{mg} / \mathrm{kg}$ in PEG300) daily for 14 days. Tumors were collected on the last day of treatment, weight and volume (as measured by digital caliper) were recorded and tissues taken for histopathology and western blotting

\section{Drug measurements}

Concentrations of NVP-BEZ235 in biological samples were determined using liquid chromatography/ mass spectrometry (LC-MS). Drug was extracted using 3-4 vol methanol containing 500 $\mathrm{ng} / \mathrm{ml}$ Olomoucin used as internal standard. Chromatography carried out on a Kinetics C18 column $(5.0 \mathrm{~cm} \times 2.1 \mathrm{~mm}$ ID, $2.6-\mu \mathrm{m}$ particle size; Phenomenex) using a $1290 \mathrm{LC}$ system with a gradient mobile phase of $0.1 \%$ formic acid/methanol at 0.6 $\mathrm{mL} / \mathrm{min}$ over 10 minutes. Detection was by LC-MS using a Agilent 6410triple quadropole in which the analyte was ionized by electrospray interface in positive mode (gas temperature 300 flow $12 \mathrm{l} / \mathrm{min}$, nebulizer 40psi, capillary voltage $4000 \mathrm{~V}$.The following transition were monitored $[\mathrm{M}+\mathrm{H}]^{+} 472.2$ to 454.2 at $50 \mathrm{~V}$ collision energy for NVPBEZ235and $[\mathrm{M}+\mathrm{H}]^{+} 299.1$ to 177.1 at $30 \mathrm{~V}$ collision energy for Olomoucin. The assay was linear in the range of $10-5000 \mathrm{nM}$.

\section{Statistical analyses}

We analyzed quantitative results either by oneway analysis of variance (multiple groups) or t test (two groups). We carried out survival analysis using KaplanMeier log-rank test. We considered a difference with $P<$ 0.05 (two-sided) statistically significant.

\section{ACKNOWLEDGMENTS}

Torin1 was generously provided by Drs. Nathanael S. Gray (Dana-Farber Cancer Institute) and David M. Sabatini (Whitehead Institute/MIT/HHMI). Novartis provided NVP-BEZ235. This work was in part supported by Cancer Research UK programme grant numbers C18339 (LC) C309/A2187 and C309/A8274 (PC, FR, $\mathrm{RB}, \mathrm{MS}$ and $\mathrm{PW}$ ). We acknowledge the support received for the Cancer Research UK \& EPSRC Cancer Imaging Centre, in association with the MRC and Department of Health (England), grant number C1060/A10334), and NHS funding to the NIHR Biomedical Research Centre. Paul Workman is a Cancer Research UK Life Fellow. We also acknowledge the support of NIH NCI: R01CA102321, P01 CA081403, and T32CA151022 (WAW, all NIH, NCI).

\section{CONFLICTS OF INTEREST}

Research have a commercial interest in the development of PI3 kinase inhibitors, and operate a rewards-to-inventors scheme. FR, PAC and PW have been involved in a commercial collaboration with Yamanouchi (now Astellas Pharma) and with Piramed Pharma and intellectual property arising from the program has been licensed to Genentech. PW was a founder of, consultant to, and Scientific Advisory Board member of Piramed Pharma (acquired by Roche). MM was an employee of Novartis Pharma AG, which is involved in the development of $\mathrm{PI} 3 \mathrm{~K} / \mathrm{mTOR}$ inhibitors.

\section{Editorial note}

This paper has been accepted based in part on peerreview conducted by another journal and the authors' response and revisions as well as expedited peer-review in Oncotarget

\section{REFERENCES}

1. Brodeur GM, Seeger RC, Schwab M, Varmus HE and Bishop JM. Amplification of N-myc in untreated human neuroblastomas correlates with advanced disease stage. Science. 1984; 224:1121-1124.

2. Schwab M, Varmus HE, Bishop JM, Grzeschik KH, Naylor SL, Sakaguchi AY, Brodeur G and Trent J. Chromosome localization in normal human cells and neuroblastomas of a gene related to c-myc. Nature. 1984; 308:288-291.

3. Cage TA, Chanthery Y, Chesler L, Grimmer M, Knight Z, Shokat K, Weiss WA and Gustafson WC. Downregulation of MYCN through PI3K Inhibition in Mouse Models of Pediatric Neural Cancer. Front Oncol. 2015; 5:111.

4. Barone G, Anderson J, Pearson AD, Petrie K and Chesler L. New strategies in neuroblastoma: Therapeutic targeting 
of MYCN and ALK. Clin Cancer Res. 2013; 19:5814-5821.

5. Swartling FJ, Grimmer MR, Hackett CS, Northcott PA, Fan QW, Goldenberg DD, Lau J, Masic S, Nguyen K, Yakovenko S, Zhe XN, Gilmer HC, Collins R, Nagaoka M, Phillips JJ, Jenkins RB, et al. Pleiotropic role for MYCN in medulloblastoma. Genes \& development. 2010; 24:10591072.

6. Jones DT, Jager N, Kool M, Zichner T, Hutter B, Sultan M, Cho YJ, Pugh TJ, Hovestadt V, Stutz AM, Rausch T, Warnatz HJ, Ryzhova M, Bender S, Sturm D, Pleier $\mathrm{S}$, et al. Dissecting the genomic complexity underlying medulloblastoma. Nature. 2012; 488:100-105.

7. Williamson D, Lu Y-J, Gordon T, Sciot R, Kelsey A, Fisher C, Poremba C, Anderson J, Pritchard-Jones K and Shipley J. Relationship Between MYCN Copy Number and Expression in Rhabdomyosarcomas and Correlation With Adverse Prognosis in the Alveolar Subtype. Journal of Clinical Oncology. 2005; 23:880-888.

8. Pfister S, Remke M, Benner A, Mendrzyk F, Toedt G, Felsberg J, Wittmann A, Devens F, Gerber NU, Joos S, Kulozik A, Reifenberger G, Rutkowski S, Wiestler OD, Radlwimmer B, Scheurlen W, et al. Outcome prediction in pediatric medulloblastoma based on DNA copy-number aberrations of chromosomes $6 \mathrm{q}$ and $17 \mathrm{q}$ and the MYC and MYCN loci. J Clin Oncol. 2009; 27:1627-1636.

9. Lee WH, Murphree AL and Benedict WF. Expression and amplification of the $\mathrm{N}$-myc gene in primary retinoblastoma. Nature. 1984; 309:458-460.

10. Goga A, Yang D, Tward AD, Morgan DO and Bishop JM. Inhibition of $\mathrm{CDK} 1$ as a potential therapy for tumors overexpressing MYC. Nat Med. 2007; 13:820-827.

11. Yang D, Liu H, Goga A, Kim S, Yuneva M and Bishop JM. Therapeutic potential of a synthetic lethal interaction between the MYC proto-oncogene and inhibition of aurora-B kinase. Proc Natl Acad Sci U S A. 2010; 107:13836-13841.

12. Otto T, Horn S, Brockmann M, Eilers U, Schuttrumpf L, Popov N, Kenney AM, Schulte JH, Beijersbergen R, Christiansen H, Berwanger B and Eilers M. Stabilization of N-Myc is a critical function of Aurora A in human neuroblastoma. Cancer Cell. 2009; 15:67-78.

13. Baryawno N, Sveinbjörnsson B, Eksborg S, Chen CS, Kogner $\mathrm{P}$ and Johnsen JI. Small-molecule inhibitors of phosphatidylinositol 3-kinase/Akt signaling inhibit Wnt/beta-catenin pathway cross-talk and suppress medulloblastoma growth. Cancer Res. 2010; 70:266-276.

14. Brockmann M, Poon E, Berry T, Carstensen A, Deubzer HE, Rycak L, Jamin Y, Thway K, Robinson SP, Roels F, Witt O, Fischer M, Chesler L and Eilers M. Small molecule inhibitors of aurora-a induce proteasomal degradation of N-myc in childhood neuroblastoma. Cancer Cell. 2013; 24:75-89.
15. Berry T, Luther W, Bhatnagar N, Jamin Y, Poon E, Sanda T, Pei D, Sharma B, Vetharoy WR, Hallsworth A, Ahmad Z, Barker K, Moreau L, Webber H, Wang W, Liu Q, et al. The ALK(F1174L) mutation potentiates the oncogenic activity of MYCN in neuroblastoma. Cancer Cell. 2012; 22:117-130.

16. Lin CJ, Nasr Z, Premsrirut PK, Porco JA, Jr., Hippo Y, Lowe SW and Pelletier J. Targeting Synthetic Lethal Interactions between Myc and the eIF4F Complex Impedes Tumorigenesis. Cell reports. 2012; 1:325-333.

17. Cole KA, Huggins J, Laquaglia M, Hulderman CE, Russell MR, Bosse K, Diskin SJ, Attiyeh EF, Sennett R, Norris G, Laudenslager M, Wood AC, Mayes PA, Jagannathan $\mathrm{J}$, Winter C, Mosse YP, et al. RNAi screen of the protein kinome identifies checkpoint kinase 1 (CHK1) as a therapeutic target in neuroblastoma. Proceedings of the National Academy of Sciences. 2011.

18. Deb-Basu D, Aleem E, Kaldis P and Felsher DW. CDK2 is required by MYC to induce apoptosis. Cell Cycle. 2006; 5:1342-1347.

19. Horiuchi D, Kusdra L, Huskey NE, Chandriani S, Lenburg ME, Gonzalez-Angulo AM, Creasman KJ, Bazarov AV, Smyth JW, Davis SE, Yaswen P, Mills GB, Esserman LJ and Goga A. MYC pathway activation in triple-negative breast cancer is synthetic lethal with CDK inhibition. J Exp Med. 2012; 209:679-696.

20. den Hollander J, Rimpi S, Doherty JR, Rudelius M, Buck A, Hoellein A, Kremer M, Graf N, Scheerer M, Hall MA, Goga A, von Bubnoff N, Duyster J, Peschel C, Cleveland JL, Nilsson JA, et al. Aurora kinases A and B are upregulated by Myc and are essential for maintenance of the malignant state. Blood. 2010; 116:1498-1505.

21. Swarbrick A, Woods SL, Shaw A, Balakrishnan A, Phua Y, Nguyen A, Chanthery Y, Lim L, Ashton LJ, Judson RL, Huskey N, Blelloch R, Haber M, Norris MD, Lengyel $\mathrm{P}$, Hackett CS, et al. miR-380-5p represses p53 to control cellular survival and is associated with poor outcome in MYCN-amplified neuroblastoma. Nature medicine. 2010; 16:1134-1140.

22. Campaner S, Doni M, Hydbring P, Verrecchia A, Bianchi L, Sardella D, Schleker T, Perna D, Tronnersjo S, Murga M, Fernandez-Capetillo O, Barbacid M, Larsson LG and Amati B. Cdk2 suppresses cellular senescence induced by the c-myc oncogene. Nat Cell Biol. 2010; 12:54-59; sup pp 51-14.

23. Molenaar JJ, Ebus ME, Geerts D, Koster J, Lamers F, Valentijn LJ, Westerhout EM, Versteeg R and Caron HN. Inactivation of CDK2 is synthetically lethal to MYCN overexpressing cancer cells. Proc Natl Acad Sci U S A. 2009; 106:12968-12973.

24. Sato M, Rodriguez-Barrueco R, Yu J, Do C, Silva JM and Gautier J. MYC is a critical target of FBXW7. Oncotarget. 2015; 6:3292-3305. doi: 10.18632/oncotarget.3203. 
25. Popov N, Wanzel M, Madiredjo M, Zhang D, Beijersbergen R, Bernards R, Moll R, Elledge SJ and Eilers M. The ubiquitin-specific protease USP28 is required for MYC stability. Nat Cell Biol. 2007; 9:765-774.

26. Yeh E, Cunningham M, Arnold H, Chasse D, Monteith T, Ivaldi G, Hahn WC, Stukenberg PT, Shenolikar S, Uchida T, Counter CM, Nevins JR, Means AR and Sears R. A signalling pathway controlling c-Myc degradation that impacts oncogenic transformation of human cells. Nat Cell Biol. 2004; 6:308-318.

27. Gustafson WC and Weiss WA. Myc proteins as therapeutic targets. Oncogene. 2010; 29:1249-1259.

28. Knoepfler PS and Kenney AM. Neural precursor cycling at sonic speed: N-Myc pedals, GSK-3 brakes. Cell Cycle. 2006; 5:47-52.

29. Sjostrom SK, Finn G, Hahn WC, Rowitch DH and Kenney AM. The Cdk1 complex plays a prime role in regulating $\mathrm{N}$-myc phosphorylation and turnover in neural precursors. Dev Cell. 2005; 9:327-338.

30. Kenney AM, Widlund HR and Rowitch DH. Hedgehog and PI-3 kinase signaling converge on Nmyc1 to promote cell cycle progression in cerebellar neuronal precursors. Development (Cambridge, England). 2004; 131:217-228.

31. Popov N, Herold S, Llamazares M, Schulein C and Eilers M. Fbw7 and Usp28 regulate myc protein stability in response to DNA damage. Cell Cycle. 2007; 6:2327-2331.

32. Wei W, Jin J, Schlisio S, Harper JW and Kaelin WG. The v-Jun point mutation allows c-Jun to escape GSK3dependent recognition and destruction by the Fbw7 ubiquitin ligase. Cancer Cell. 2005; 8:25-33.

33. Koepp DM, Schaefer LK, Ye X, Keyomarsi K, Chu C, Harper JW and Elledge SJ. Phosphorylation-dependent ubiquitination of cyclin E by the SCFFbw7 ubiquitin ligase. Science. 2001; 294:173-177.

34. O’Neil J, Grim J, Strack P, Rao S, Tibbitts D, Winter C, Hardwick J, Welcker M, Meijerink JP, Pieters R, Draetta G, Sears R, Clurman BE and Look AT. FBW7 mutations in leukemic cells mediate NOTCH pathway activation and resistance to gamma-secretase inhibitors. J Exp Med. 2007; 204:1813-1824.

35. Opel D, Poremba C, Simon T, Debatin KM and Fulda S. Activation of Akt predicts poor outcome in neuroblastoma. Cancer Res. 2007; 67:735-745.

36. Fulda S. The PI3K/Akt/mTOR pathway as therapeutic target in neuroblastoma. Curr Cancer Drug Targets. 2009; 9:729-737.

37. Chesler L, Schlieve C, Goldenberg DD, Kenney A, Kim G, McMillan A, Matthay KK, Rowitch D and Weiss WA. Inhibition of phosphatidylinositol 3-kinase destabilizes Mycn protein and blocks malignant progression in neuroblastoma. Cancer Res. 2006; 66:8139-8146.

38. Anastassiadis T, Deacon SW, Devarajan K, Ma H and Peterson JR. Comprehensive assay of kinase catalytic activity reveals features of kinase inhibitor selectivity. Nat Biotechnol. 2011.

39. Faisal A, Vaughan L, Bavetsias V, Sun C, Atrash B, Avery S, Jamin Y, Robinson SP, Workman P, Blagg J, Raynaud FI, Eccles SA, Chesler L and Linardopoulos S. The Aurora kinase inhibitor CCT137690 downregulates MYCN and sensitizes MYCN-amplified neuroblastoma in vivo. Mol Cancer Ther. 2011.

40. Yap TA, Bjerke L, Clarke PA and Workman P. Drugging PI3K in cancer: refining targets and therapeutic strategies. Curr Opin Pharmacol. 2015; 23:98-107.

41. Workman P and Clarke P. PI3 Kinase in Cancer: From Biology to Clinic. American Society of Clinical Oncology educational book / ASCO American Society of Clinical Oncology Meeting. 2012:e93-98.

42. Raynaud FI, Eccles S, Clarke PA, Hayes A, Nutley B, Alix S, Henley A, Di-Stefano F, Ahmad Z, Guillard S, Bjerke LM, Kelland L, Valenti M, Patterson L, Gowan S, de Haven Brandon A, et al. Pharmacologic characterization of a potent inhibitor of class I phosphatidylinositide 3-kinases. Cancer Res. 2007; 67:5840-5850.

43. Al-Saffar NM, Jackson LE, Raynaud FI, Clarke PA, Ramirez de Molina A, Lacal JC, Workman P and Leach MO. The phosphoinositide 3-kinase inhibitor PI-103 downregulates choline kinase alpha leading to phosphocholine and total choline decrease detected by magnetic resonance spectroscopy. Cancer Res. 2010; 70:5507-5517.

44. Raynaud FI, Eccles SA, Patel S, Alix S, Box G, Chuckowree I, Folkes A, Gowan S, De Haven Brandon A, Di Stefano F, Hayes A, Henley AT, Lensun L, Pergl-Wilson G, Robson A, Saghir N, et al. Biological properties of potent inhibitors of class I phosphatidylinositide 3-kinases: from PI-103 through PI-540, PI-620 to the oral agent GDC-0941. Mol Cancer Ther. 2009; 8:1725-1738.

45. Guillard S, Clarke PA, Te Poele R, Mohri Z, Bjerke L, Valenti M, Raynaud F, Eccles SA and Workman P. Molecular pharmacology of phosphatidylinositol 3-kinase inhibition in human glioma. Cell Cycle. 2009; 8:443-453.

46. Chesler L, Schlieve C, Goldenberg D, Kenney A, Kim G, McMillan A, Matthay K, Rowitch D and Weiss W. Inhibition of phosphatidylinositol 3-kinase destabilizes Mycn protein and blocks malignant progression in neuroblastoma. Cancer Res. 2006; 66:8139-8146.

47. Maira SM, Stauffer F, Brueggen J, Furet P, Schnell C, Fritsch C, Brachmann S, Chene P, De Pover A, Schoemaker K, Fabbro D, Gabriel D, Simonen M, Murphy L, Finan P, Sellers W, et al. Identification and characterization of NVPBEZ235, a new orally available dual phosphatidylinositol 3-kinase/mammalian target of rapamycin inhibitor with potent in vivo antitumor activity. Mol Cancer Ther. 2008; 7:1851-1863.

48. Liu Q, Chang JW, Wang J, Kang SA, Thoreen CC, Markhard A, Hur W, Zhang J, Sim T, Sabatini DM and 
Gray NS. Discovery of 1-(4-(4-Propionylpiperazin-1-yl)3-(trifluoromethyl)phenyl)-9-(quinolin-3-yl)benzo[h][1,6] naphthyridin-2(1H)-one as a Highly Potent, Selective Mammalian Target of Rapamycin (mTOR) Inhibitor for the Treatment of Cancer. Journal of Medicinal Chemistry. 2010; 53:7146-7155.

49. Kong D and Yamori T. ZSTK474 is an ATP-competitive inhibitor of class I phosphatidylinositol 3 kinase isoforms. Cancer Sci. 2007; 98:1638-1642.

50. Janku F, Tsimberidou AM, Garrido-Laguna I, Wang X, Luthra R, Hong DS, Naing A, Falchook GS, Moroney JW, Piha-Paul SA, Wheler JJ, Moulder SL, Fu S and Kurzrock R. PIK3CA mutations in patients with advanced cancers treated with PI3K/AKT/mTOR axis inhibitors. Mol Cancer Ther. 2011; 10:558-565.

51. Workman P, Clarke PA, Raynaud FI and van Montfort RL. Drugging the PI3 kinome: from chemical tools to drugs in the clinic. Cancer Res. 2010; 70:2146-2157.

52. Shuttleworth SJ, Silva FA, Cecil AR, Tomassi CD, Hill TJ, Raynaud FI, Clarke PA and Workman P. Progress in the preclinical discovery and clinical development of class I and dual class I/IV phosphoinositide 3-kinase (PI3K) inhibitors. Curr Med Chem. 2011; 18:2686-2714.

53. Armstrong DK, Kaufmann SH, Ottaviano YL, Furuya Y, Buckley JA, Isaacs JT and Davidson NE. Epidermal growth factor-mediated apoptosis of MDA-MB-468 human breast cancer cells. Cancer Res. 1994; 54:5280-5283.

54. Shimura T, Takenaka Y, Tsutsumi S, Hogan V, Kikuchi A and Raz A. Galectin-3, a novel binding partner of betacatenin. Cancer Res. 2004; 64:6363-6367.

55. Nakahara I, Miyamoto M, Shibata T, Akashi-Tanaka S, Kinoshita T, Mogushi K, Oda K, Ueno M, Takakura N, Mizushima H, Tanaka $\mathrm{H}$ and Ohta T. Up-regulation of PSF1 promotes the growth of breast cancer cells. Genes Cells. 2010; 15:1015-1024.

56. Chen CR, Kang Y and Massagué J. Defective repression of c-myc in breast cancer cells: A loss at the core of the transforming growth factor beta growth arrest program. Proc Natl Acad Sci U S A. 2001; 98:992-999.

57. Sahin O, Fröhlich H, Löbke C, Korf U, Burmester S, Majety M, Mattern J, Schupp I, Chaouiya C, Thieffry D, Poustka A, Wiemann S, Beissbarth T and Arlt D. Modeling ERBB receptor-regulated $\mathrm{G} 1 / \mathrm{S}$ transition to find novel targets for de novo trastuzumab resistance. BMC Syst Biol. 2009; 3:1.

58. Wang C, Mayer JA, Mazumdar A, Fertuck K, Kim H, Brown $\mathrm{M}$ and Brown PH. Estrogen induces c-myc gene expression via an upstream enhancer activated by the estrogen receptor and the AP-1 transcription factor. Mol Endocrinol. 2011; 25:1527-1538.

59. Kong D, Okamura M, Yoshimi $H$ and Yamori T. Antiangiogenic effect of ZSTK474, a novel phosphatidylinositol 3-kinase inhibitor. Eur J Cancer. 2009; 45:857-865.
60. Thoreen CC, Kang SA, Chang JW, Liu Q, Zhang J, Gao Y, Reichling LJ, Sim T, Sabatini DM and Gray NS. An ATP-competitive mammalian target of rapamycin inhibitor reveals rapamycin-resistant functions of mTORC1. J Biol Chem. 2009; 284:8023-8032.

61. Welcker M, Orian A, Jin J, Grim JE, Grim JA, Harper JW, Eisenman RN and Clurman BE. The Fbw7 tumor suppressor regulates glycogen synthase kinase 3 phosphorylationdependent c-Myc protein degradation. Proc Natl Acad Sci U S A. 2004; 101:9085-9090.

62. Sarbassov DD, Guertin DA, Ali SM and Sabatini DM. Phosphorylation and regulation of Akt/PKB by the rictormTOR complex. Science. 2005; 307:1098-1101.

63. Weiss WA, Aldape K, Mohapatra G, Feuerstein BG and Bishop JM. Targeted expression of MYCN causes neuroblastoma in transgenic mice. EMBO J. 1997; 16:29852995.

64. Yaguchi S, Fukui Y, Koshimizu I, Yoshimi H, Matsuno T, Gouda H, Hirono S, Yamazaki K and Yamori T. Antitumor activity of ZSTK474, a new phosphatidylinositol 3-kinase inhibitor. J Natl Cancer Inst. 2006; 98:545-556.

65. Harris AW, Pinkert CA, Crawford M, Langdon WY, Brinster RL and Adams JM. The E mu-myc transgenic mouse. A model for high-incidence spontaneous lymphoma and leukemia of early B cells. J Exp Med. 1988; 167:353371.

66. Baumbach WR, Keath EJ and Cole MD. A mouse c-myc retrovirus transforms established fibroblast lines in vitro and induces monocyte-macrophage tumors in vivo. J Virol. 1986; 59:276-283.

67. Amundadottir LT, Nass SJ, Berchem GJ, Johnson MD and Dickson RB. Cooperation of TGF alpha and c-Myc in mouse mammary tumorigenesis: coordinated stimulation of growth and suppression of apoptosis. Oncogene. 1996; 13:757-765.

68. Thorgeirsson SS and Santoni-Rugiu E. Transgenic mouse models in carcinogenesis: interaction of c-myc with transforming growth factor alpha and hepatocyte growth factor in hepatocarcinogenesis. Br J Clin Pharmacol. 1996; 42:43-52.

69. McCormack SJ, Weaver Z, Deming S, Natarajan G, Torri J, Johnson MD, Liyanage M, Ried T and Dickson RB. Myc/p53 interactions in transgenic mouse mammary development, tumorigenesis and chromosomal instability. Oncogene. 1998; 16:2755-2766.

70. Sheppard RD, Samant SA, Rosenberg M, Silver LM and Cole MD. Transgenic N-myc mouse model for indolent $\mathrm{B}$ cell lymphoma: tumor characterization and analysis of genetic alterations in spontaneous and retrovirally accelerated tumors. Oncogene. 1998; 17:2073-2085.

71. Schmitt CA, Wallace-Brodeur RR, Rosenthal CT, McCurrach ME and Lowe SW. DNA damage responses and chemosensitivity in the E mu-myc mouse lymphoma model. Cold Spring Harb Symp Quant Biol. 2000; 65:499-510. 
72. Yu D and Thomas-Tikhonenko A. A non-transgenic mouse model for B-cell lymphoma: in vivo infection of p53-null bone marrow progenitors by a Myc retrovirus is sufficient for tumorigenesis. Oncogene. 2002; 21:1922-1927.

73. Soucek L and Evan GI. The ups and downs of Myc biology. Current opinion in genetics \& development. 2010; 20:9195.

74. Gouw AM, Toal GG and Felsher DW. Metabolic vulnerabilities of MYC-induced cancer. Oncotarget. 2016; 7:29879-80. doi: 10.18632/oncotarget.7223.

75. Gabay M, Li Y and Felsher DW. MYC activation is a hallmark of cancer initiation and maintenance. Cold Spring Harbor perspectives in medicine. 2014; 4.

76. Jain M, Arvanitis C, Chu K, Dewey W, Leonhardt E, Trinh M, Sundberg CD, Bishop JM and Felsher DW. Sustained loss of a neoplastic phenotype by brief inactivation of MYC. Science. 2002; 297:102-104.

77. Annibali D, Whitfield JR, Favuzzi E, Jauset T, Serrano E, Cuartas I, Redondo-Campos S, Folch G, Gonzalez-Junca A, Sodir NM, Masso-Valles D, Beaulieu ME, Swigart LB, Mc Gee MM, Somma MP, Nasi S, et al. Myc inhibition is effective against glioma and reveals a role for Myc in proficient mitosis. Nature communications. 2014; 5:4632.

78. Soucek L, Whitfield JR, Sodir NM, Masso-Valles D, Serrano E, Karnezis AN, Swigart LB and Evan GI. Inhibition of Myc family proteins eradicates KRas-driven lung cancer in mice. Genes \& development. 2013; 27:504513.

79. Soucek L, Whitfield J, Martins CP, Finch AJ, Murphy DJ, Sodir NM, Karnezis AN, Swigart LB, Nasi S and Evan GI. Modelling Myc inhibition as a cancer therapy. Nature. 2008; 455:679-683.

80. Segerström L, Baryawno N, Sveinbjörnsson B, Wickström M, Elfman L, Kogner P and Johnsen JI. Effects of small molecule inhibitors of PI3K/Akt/mTOR signaling on neuroblastoma growth in vitro and in vivo. Int $\mathrm{J}$ Cancer. 2011; 129:2958-2965.

81. Clarke PA and Workman P. Phosphatidylinositide-3-kinase inhibitors: addressing questions of isoform selectivity and pharmacodynamic/predictive biomarkers in early clinical trials. J Clin Oncol. 2012; 30:331-333.

82. Arrowsmith $\mathrm{CH}$, Audia JE, Austin C, Baell J, Bennett J, Blagg J, Bountra C, Brennan PE, Brown PJ, Bunnage ME, Buser-Doepner C, Campbell RM, Carter AJ, Cohen P, Copeland RA, Cravatt B, et al. The promise and peril of chemical probes. Nat Chem Biol. 2015; 11:536-541.

83. Collins I and Workman P. New approaches to molecular cancer therapeutics. Nat Chem Biol. 2006; 2:689-700.

84. Hemann MT, Bric A, Teruya-Feldstein J, Herbst A, Nilsson JA, Cordon-Cardo C, Cleveland JL, Tansey WP and Lowe SW. Evasion of the p53 tumour surveillance network by tumour-derived MYC mutants. Nature. 2005; 436:807-811.

85. Adachi S, Obaya AJ, Han Z, Ramos-Desimone N, Wyche
$\mathrm{JH}$ and Sedivy JM. c-Myc is necessary for DNA damageinduced apoptosis in the $\mathrm{G}(2)$ phase of the cell cycle. Molecular and cellular biology. 2001; 21:4929-4937.

86. Louis SF, Vermolen BJ, Garini Y, Young IT, Guffei A, Lichtensztejn Z, Kuttler F, Chuang TC, Moshir S, Mougey V, Chuang AY, Kerr PD, Fest T, Boukamp P and Mai $\mathrm{S}$. c-Myc induces chromosomal rearrangements through telomere and chromosome remodeling in the interphase nucleus. Proc Natl Acad Sci U S A. 2005; 102:9613-9618.

87. Pourdehnad M, Truitt ML, Siddiqi IN, Ducker GS, Shokat $\mathrm{KM}$ and Ruggero D. Myc and mTOR converge on a common node in protein synthesis control that confers synthetic lethality in Myc-driven cancers. Proc Natl Acad Sci U S A. 2013; 110:11988-11993.

88. Lin CJ, Cencic R, Mills JR, Robert F and Pelletier J. c-Myc and eIF4F are components of a feedforward loop that links transcription and translation. Cancer Res. 2008; 68:53265334.

89. Hsieh AC, Costa M, Zollo O, Davis C, Feldman ME, Testa JR, Meyuhas O, Shokat KM and Ruggero D. Genetic dissection of the oncogenic mTOR pathway reveals druggable addiction to translational control via 4EBPeIF4E. Cancer Cell. 2010; 17:249-261.

90. Wiegering A, Uthe FW, Jamieson T, Ruoss Y, Huttenrauch M, Kuspert M, Pfann C, Nixon C, Herold S, Walz S, Taranets L, Germer CT, Rosenwald A, Sansom OJ and Eilers M. Targeting Translation Initiation Bypasses Signaling Crosstalk Mechanisms That Maintain High MYC Levels in Colorectal Cancer. Cancer discovery. 2015; 5:768-781.

91. Ilic N, Utermark T, Widlund HR and Roberts TM. PI3Ktargeted therapy can be evaded by gene amplification along the MYC-eukaryotic translation initiation factor 4E (eIF4E) axis. Proc Natl Acad Sci U S A. 2011; 108:E699-708.

92. Evageliou NF and Hogarty MD. Disrupting polyamine homeostasis as a therapeutic strategy for neuroblastoma. Clin Cancer Res. 2009; 15:5956-5961.

93. Dang CV. Therapeutic Targeting of Myc-Reprogrammed Cancer Cell Metabolism. Cold Spring Harb Symp Quant Biol. 2011.

94. Dang CV. The interplay between MYC and HIF in the Warburg effect. Ernst Schering Found Symp Proc. 2007; :35-53.

95. Dang CV, Kim JW, Gao P and Yustein J. The interplay between MYC and HIF in cancer. Nat Rev Cancer. 2008; 8:51-56.

96. Skehan P, Storeng R, Scudiero D, Monks A, McMahon J, Vistica D, Warren JT, Bokesch H, Kenney S and Boyd MR. New colorimetric cytotoxicity assay for anticancer-drug screening. J Natl Cancer Inst. 1990; 82:1107-1112.

97. Workman P and Collins I. Probing the probes: fitness factors for small molecule tools. Chem Biol. 2010; 17:561577. 
98. Arrowsmith $\mathrm{CH}$, Audia JE, Austin C, Baell J, Bennett J, Blagg J, Bountra C, Brennan PE, Brown PJ, Bunnage ME, Buser-Doepner C, Campbell RM, Carter AJ, Cohen P, Copeland RA, Cravatt B, et al. Corrigendum: The promise and peril of chemical probes. Nat Chem Biol. 2015; 11:887.

99. Blagg J and Workman P. Chemical biology approaches to target validation in cancer. Curr Opin Pharmacol. 2014; 17:87-100.
100. Workman P, Aboagye EO, Balkwill F, Balmain A, Bruder G, Chaplin DJ, Double JA, Everitt J, Farningham DAH, Glennie MJ, Kelland LR, Robinson V, Stratford IJ, Tozer GM, Watson S, Wedge SR, et al. Guidelines for the welfare and use of animals in cancer research. Br J Cancer. 2010; 102:1555-1577. 